\title{
Planar droplet sizing for studying the influence of ethanol admixture on the spray structure of gasoline sprays
}

\author{
Matthias Koegl ${ }^{1,2} \cdot$ Yogeshwar Nath Mishra $^{1,3} \cdot$ Kevin Baderschneider $^{1} \cdot$ Chris Conrad $^{1,2} \cdot$ Bastian Lehnert $^{1,2}$. \\ Stefan Will ${ }^{1,2} \cdot$ Lars Zigan ${ }^{1,2}$
}

Received: 19 May 2020 / Revised: 23 July 2020 / Accepted: 20 August 2020 / Published online: 9 September 2020

(c) The Author(s) 2020

\begin{abstract}
A novel planar droplet sizing (PDS) technique based on laser-induced fluorescence (LIF) and Mie-scattering is utilized for the characterization of the spray structure under gasoline direct-injection spark-ignition (DISI) conditions. Fuel effects on the spray structure and cyclic variations are studied for a gasoline surrogate fuel (Toliso, consisting of 65 vol. $\%$ isooctane and 35 vol.\% toluene) and the gasoline-ethanol blend E20 (20 vol.\% ethanol admixture). Sauter mean diameter (SMD) results are compared with those from phase-Doppler anemometry (PDA) measurements showing good agreement especially at early points in time (up to $1.2 \mathrm{~ms}$ after start of injection). The liquid spray propagation and SMD are very similar for both fuels indicating similar atomization behavior. Both investigated fuels show comparable cyclic variations of the spray shape. A larger width and slightly larger droplet sizes are observed for the E20 spray when stronger evaporation occurs (at $2 \mathrm{~ms}$ ). At these later points in time, the PDS-measured droplet sizes differ from the PDA-results. Here the limitation of the PDS-technique becomes obvious as a partial evaporation of the droplets may lead to large systematic errors. A numerical simulation of single droplets is provided for clarification of issues of droplet evaporation in PDS.
\end{abstract}

Matthias Koegl

matthias.koegl@fau.de

1 Lehrstuhl für Technische Thermodynamik (LTT),

Friedrich-Alexander-Universität Erlangen-Nürnberg (FAU),

91058 Erlangen, Germany

2 Erlangen Graduate School in Advanced Optical

Technologies, FAU, 91052 Erlangen, Germany

3 Present Address: NASA-Jet Propulsion Laboratory,

California Institute of Technology, 4800 Oak Grove Drive,

Pasadena, CA 91109, USA 


\section{Graphic abstract}

\section{Planar droplet sizing for studying the influence of ethanol admixture on the spray structure of gasoline sprays}
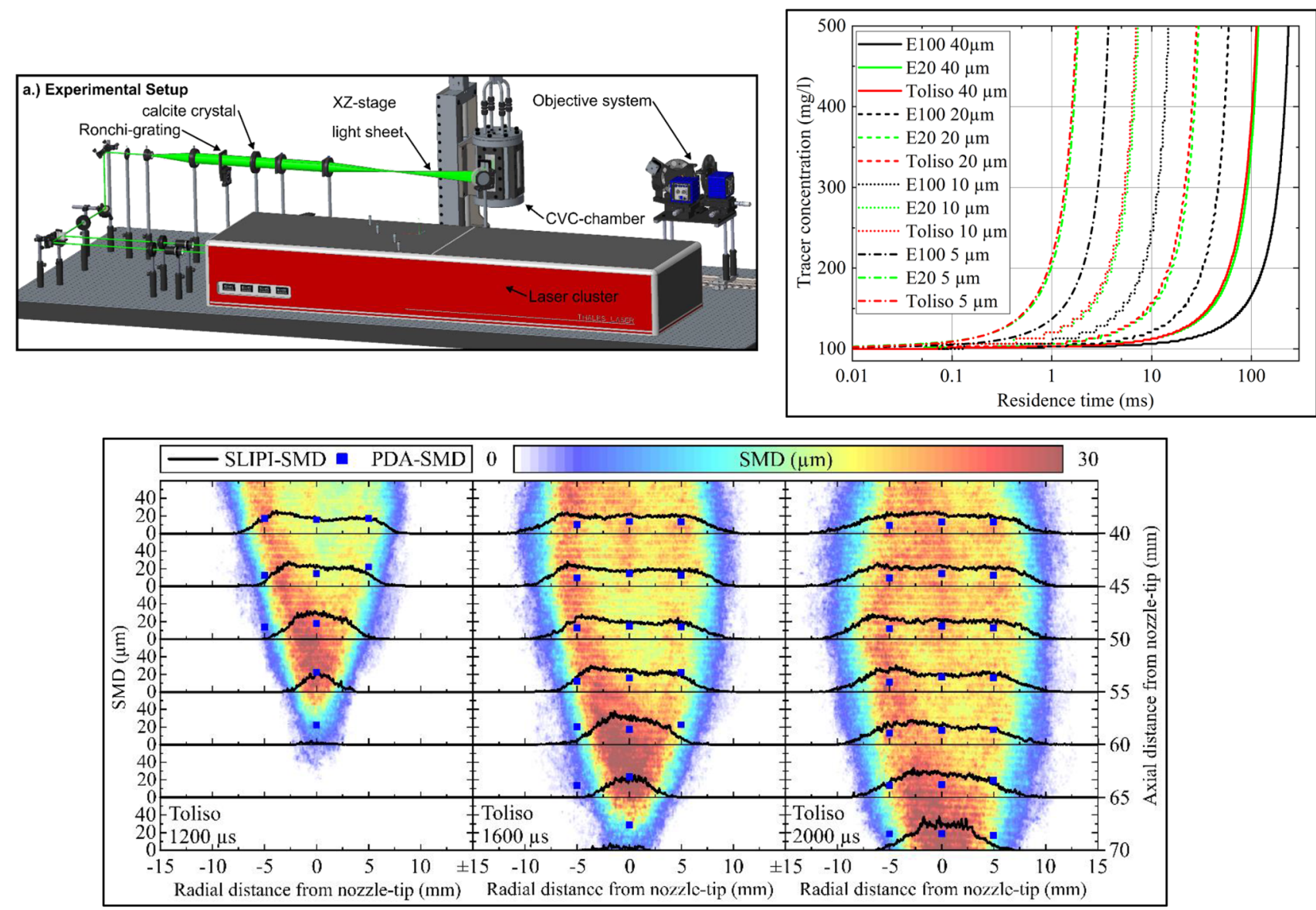

\section{Introduction}

The spray formation controls the combustion process of IC engines in terms of pollutant emissions, efficiency and consequently $\mathrm{CO}_{2}$-emissions. The atomization and mixture formation processes of gasoline direct injection spark ignition (DISI) engines are very complex. Atomization and mixture formation are mainly governed by the thermo-physical properties of the fuel and they affect subsequent processes like the soot formation essentially (Chen and Stone 2011; Shirazi et al. 2019; Storch et al. 2015; Koegl et al. 2019a).

The usage of alternative biofuels like ethanol and butanol may contribute to an effective reduction of the $\mathrm{CO}_{2}$-emissions, but their utilization could rise the complexity of the mixture formation and combustion processes. Previous studies showed that an ethanol admixture to gasoline could lead to a soot reduction of DISI-engines, which is mainly caused by the chemical fuel properties (Fournier et al. 2016; Storch et al. 2014). Under certain conditions, however, an ethanol admixture to gasoline can result in more distinct soot formation of a DISI-engine (Chen and Stone 2011; Storch et al. 2014, 2015; Koegl et al. 2018a). This is caused by the different atomization and evaporation behavior due to the fuels' physical properties. Especially the increased surface tension and liquid fuel viscosity may increase the resistance to droplet breakup (Shirazi et al. 2019). The viscosity of gasoline rises by up to $20 \%$ for addition of $15 \mathrm{vol} . \%$ alcohol (Christensen et al. 2011). However, under DISI conditions studied in an injection chamber, the effect of viscosity of different fuel components on atomization was not significant. Zigan et al. (2010) reported variations in SMD of just $5-7 \%$ when the liquid viscosity was varied by a factor 
of about 2. In this case, different single component fuels were studied at low ambient temperature $(293 \mathrm{~K}, 1.5 \mathrm{MPa})$. However, there are no systematic experiments available on the atomization behavior of gasoline-ethanol blends.

Knorsch et al. (2013) found a larger Sauter mean diameter (SMD) for ethanol droplets as compared to isooctane under conditions with high evaporation rate ( $0.8 \mathrm{MPa}$ ambient pressure and at $673 \mathrm{~K}$ gas temperature). This can be explained by the fact that ethanol admixture leads to an increase of the evaporation enthalpy of the fuel mixture. This could result in a decrease of the evaporation rate with increasing ethanol content and worse mixture preparation. Storch et al. (2016a) conducted a mixing study in a transparent DISI engine under late injection timing conditions and found a very similar mixture for isooctane and E20 (consisting of isooctane and 20\% ethanol). Partially, for E20 even a higher probability of fuel-rich zones was found compared to isooctane, while E85 (containing 85\% ethanol) and pure ethanol again lead to leaner mixtures. It was concluded that the mixture formation was controlled by the evaporation enthalpy of ethanol. However, effects of atomization could not be separated so that further experiments are necessary to understand the complex process chain.

Non-invasive optical techniques are suitable to allow for further optimization of injection and spray processes. 2D diagnostics are preferable as they provide insights into the complex spray structure. Especially, the droplet size is an essential quantity to describe sprays, and manifold approaches have been proposed to enable a 2D measurement in sprays. Measurement techniques like shadowgraphy are used for droplet sizing in dilute spray regions (Welss et al. 2018; Moon et al. 2005), and also interferometric Mie Imaging (IMI) (or Interferometric Mie Imaging for Droplet Sizing, ILIDS) is employed (Kawaguchi et al. 2002; Mounaïm-Rousselle and Pajot 1999). Other planar droplet sizing techniques are based on the LIF/Mie-ratio (Gal et al. 1999; Domann and Hardalupas 2001a,b, 2003; Domann et al. 2002; Frackowiak and Tropea 2010a,b; Charalampous and Hardalupas 2011a,b; Koegl et al. 2018b), which is a combination of laser-induced fluorescence (LIF) and Miescattering (Mie), the LIEF/Mie ratio (LIEF-laser-induced exciplex fluorescence) (Zeng et al. 2013) or the Raman/Mie ratio (Malarski et al. 2009).

The LIF/Mie ratio technique can be utilized for spray characterization in terms of determination of the SMD (Sauter mean diameter). The LIF/Mie ratio technique is based on the volumetric dependence $\left(d^{3}\right)$ of the LIFsignal and the square dependence $\left(d^{2}\right)$ of the Mie-signal (which is proportional to the droplet surface) of droplets illuminated with a laser light source ( $\mathrm{Gal}$ et al. 1999; Domann and Hardalupas 2001a,b, 2003; Domann et al. 2002; Frackowiak and Tropea 2010a,b; Charalampous and Hardalupas 2011a,b; Koegl et al. 2018b). The LIF- and the Mie-Signals $S_{\mathrm{LIF}}$ and $S_{\mathrm{Mie}}$ as a function of the droplet diameter $d_{\text {droplet }}$ can be expressed by the following equations (Gal et al. 1999):

$S_{\mathrm{LIF}}=a_{\mathrm{LIF}} \times d_{\text {droplet }}^{3}$

$S_{\text {Mie }}=a_{\text {Mie }} \times d_{\text {droplet }}^{2}$

Experimental parameters like the laser fluence and the collection angle are included by the constants $a_{\mathrm{LIF}}$ and $a_{\mathrm{Mie}}$. Mie-exponents above two are possible due to morphology-dependent resonance (MDR) effects. The LIFexponent shows a strong dependence on the absorption of the liquid solution. A low absorption leads to exponents of three according to the literature, while stronger absorption may lead to a decrease of the exponent down to two (Gal et al. 1999).

The initially qualitative LIF/Mie ratio must be calibrated using additional measurement techniques to image the SMD in the spray. phase-Doppler anemometry (PDA) measurements in the same spray (Koegl et al. 2019a; Gal et al. 1999) or monodisperse droplet LIF/Mie measurements with a droplet generator (Domann and Hardalupas 2001b; Koegl et al. 2018b,c) are usually applied for that purpose. Single droplet LIF/Mie data is advantageous for calibration of instantaneous spray images as the data is applicable for other spray systems as well. Furthermore, the same detection system can be used for calibration in a droplet chain and the actual spray measurements. Averaged PDA data acquired in the same spray is not universally applicable and may introduce large measurement uncertainties (e.g. in transient sprays or intermittent injections) as these sprays may show large cyclic variations in spray shape and SMD. However, when using a droplet generator, it must be able to produce a wide range of droplet sizes that are relevant for the respective spray.

The LIF-signal can either be created by the aromatic components of a multi-component fuel itself (Park et al. 2002) or by adding a dye to the fuel (Koegl et al. 2019a; Mishra et al. 2014). Aromatic hydrocarbons, which are present in commercial automotive fuels at high percentages, absorb laser light within the UV region. A visible wavelength should be preferred for excitation of the dye in order to avoid interference with fluorescence of excited fuel components, which may falsify the data.

Many investigations on droplet sizing using LIF/Mie ratio in alcohol or water sprays already exist in the literature (Koegl et al. 2018b,c, 2019a; Mishra et al. 2014, 2017, 2019; Storch et al. 2016b). The tracer Eosin Y, which was mainly used in the previous studies, is not soluble in alkanes or gasoline fuels (Durst et al. 2018). The tracer options for alkanes, oils and gasoline are more limited 
and mainly pyrromethene and its derivatives (e.g., 5978C9, 597-C8) are applied, but the fluorescence strongly depends on temperature so that this dye is mainly used for thermometry (Depredurand et al. 2008, 2010; Palmer et al. 2018). The tracer Nile red $\left(\mathrm{C}_{20} \mathrm{H}_{18} \mathrm{~N}_{2} \mathrm{O}_{2}\right)$ is one promising tracer, which is commonly used in microfluidic and in biology applications (Zhang et al. 2018; Lin et al. 2014; Greenspan and Fowler 1985). It is also soluble in realworld fuels (Durst et al. 2018). The fluorescence signal of Nile red was already characterized in combination with various fuels (Koegl et al. 2019b). Furthermore, the impact of ethanol admixture on the respective LIF and Mie signals of monodisperse gasoline droplets of a droplet generator were also studied in a previous work of the authors (Koegl et al. 2019c). The droplets were investigated at relevant DISI engine conditions with sizes from 20 to $50 \mu \mathrm{m}$. The individual LIF- and Mie-signals were applied to deduce SMD calibration curves depending on dye concentration, laser-fluence, temperature and fuel composition (Koegl et al. 2019c). Major challenges of using dyes for LIF/Mie droplet sizing are its varying concentration during evaporation and related temperature changes, which may introduce large errors in SMD. So far, only few studies (Koegl et al. 2018b, 2019a) exist that address these issues, but no systematic investigation has been conducted for gasoline sprays and gasoline-ethanol blends. Consequently, effects of the evaporation on the measurement uncertainty of PDS are quantified in the framework of the present study for the first time.

In the present study, the spray formation of gasolineethanol fuel blends is studied in a constant volume chamber with the LIF/Mie ratio technique. For this purpose, the PDS-technique is combined with 2-phase structured laser illumination planar imaging (SLIPI) to reduce effects of multiply scattered light in denser spray regions [for details see (Koegl et al. 2019a; Mishra et al. 2017; Storch et al. 2016b)]. The LIF/Mie results are calibrated with the respective single droplet data of a droplet generator (Koegl et al. 2019c). Afterwards, the fuel-dependent spray structure is described in terms of the SMD, and the data is compared to point-wise PDA-measurements. Fuel effects on spray formation are described for a gasoline surrogate fuel ("Toliso" consisting of isooctane and toluene) and a blend with ethanol (E20). The limitations of the presented LIF/Mie-technique under conditions with low evaporation rate (gas and fuel temperature $293 \mathrm{~K}$, injection pressure $16 \mathrm{MPa}$, chamber pressure $0.2 \mathrm{MPa}$ ) are presented. For this purpose, a numerical simulation of the single droplet evaporation process is provided as well, which describes different sources of error (such as temperature and dye concentration effects) on the accuracy of the PDS technique. Critical time scales are estimated when evaporation effects play a significant role under the present injection conditions. The effect of the evaporation rate on the accuracy is also determined for various base fuels, which show different boiling points and evaporation enthalpies.

\section{Experimental and numerical setups}

\subsection{Planar droplet sizing using SLIPI-LIF/Mie}

The DISI-sprays are analyzed in a constant volume chamber (CVC) with the 2p-SLIPI-technique (Storch et al. 2016b). The experimental setup for the simultaneous detection of the LIF- and Mie-signals of laser-illuminated fuel sprays is shown in Fig. 1. The technique uses two modulated sub images with a $180^{\circ}$ phase shift to suppress multiply scattered light. The two laser pulses for the SLIPI technique are generated by a Thales laser cluster (Nd:YAG, $532 \mathrm{~nm}$, pulse duration $6 \mathrm{~ns}$, top hat beam profile, height: $115 \mathrm{~mm}$, thickness: $0.4 \mathrm{~mm}$, laser fluence: $48 \mathrm{~mJ} / \mathrm{cm}^{2}$ ). The modulation is generated by a square Ronchi grating leading to lines with $0.35 \mathrm{~mm}$ height with an equidistant spacing of $0.7 \mathrm{~mm}$ in the spray. The spatial phase shift is generated by a calcite crystal and two cross-polarized laser beams. The horizontally polarized laser pulse passes through the crystal and maintains the same path (ordinary ray), while the vertically polarized laser pulse is displaced (extraordinary ray) (Storch et al. 2016b). The spatial shift is determined by the thickness of the calcite crystal. A detailed description of the working principle of $2 p$-SLIPI and the setup can be found in references (Storch et al. 2016b; Mishra et al. 2019). The LIF and Mie signals are recorded simultaneously using a specially designed objective system, which is equipped with a macroscopic objective (135 mm, 2.8/135, Pentacon, Germany). The signal is spectrally divided by a beam splitter (Transmission: $70 \%$ LIF, 30\% Mie) just after the objective, and the individual signals are recorded with two identical double-shutter sCMOS cameras (LaVision GmbH, Germany; 2560×2160 pixels, nominal pixel resolution $37.3 \mu \mathrm{m} / \mathrm{pixel})$. The LIF and Mie signals are detected in different spectral regions by using appropriate filters [LIF: 532 notch filter, 17 FWHM; Mie: $532 \mathrm{~nm}$ laser line pass filter (1 nm FWHM)], which are mounted in front of the cameras. To optimize the signal detection at constant laser power and at different observation time points, motorized filter wheels equipped with a set of ND-filters (ND 0, ND 0.3, ND 0.6, ND 1, ND 1.3) are mounted in front of the individual cameras. The cameras are operated in double-shutter mode for 2-phase SLIPI. The time delay between the laser pulses and the two sub images is $0.75 \mu$ s to freeze the spray motion. The five-hole solenoid DISI injector (BOSCH, Germany) with the corresponding spray targeting is shown in Fig. 2.

The injector has a bore diameter of $168 \mu \mathrm{m}$ and a length-to-diameter ratio $(1 / d)$ of 1.7 . The injection pressure 


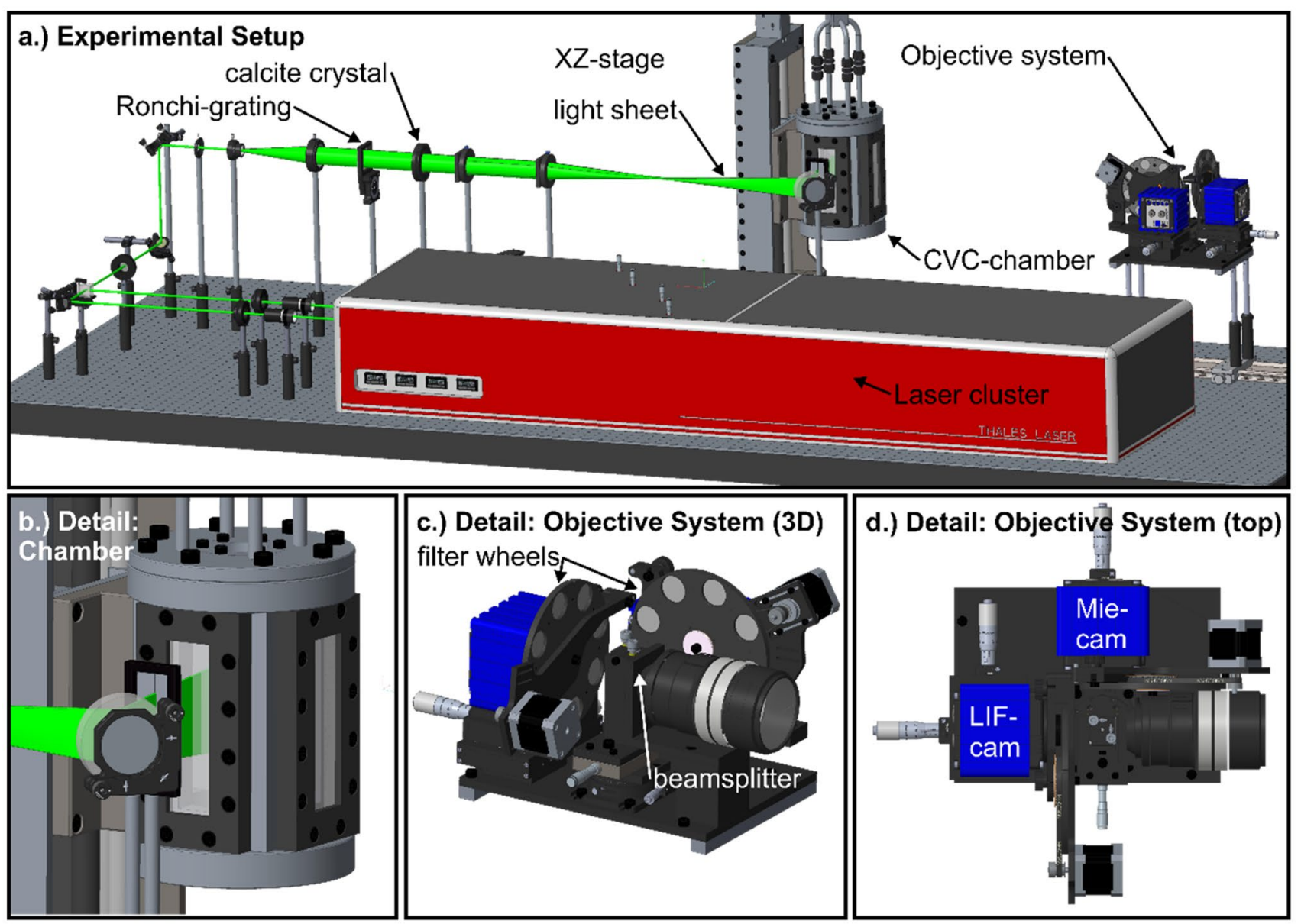

Fig. 1 Experimental setup for the simultaneous detection of the optical LIF and Mie signals of laser illuminated fuel sprays

Fig. 2 Five-hole solenoid DISI Injector with detailed spray targeting regions

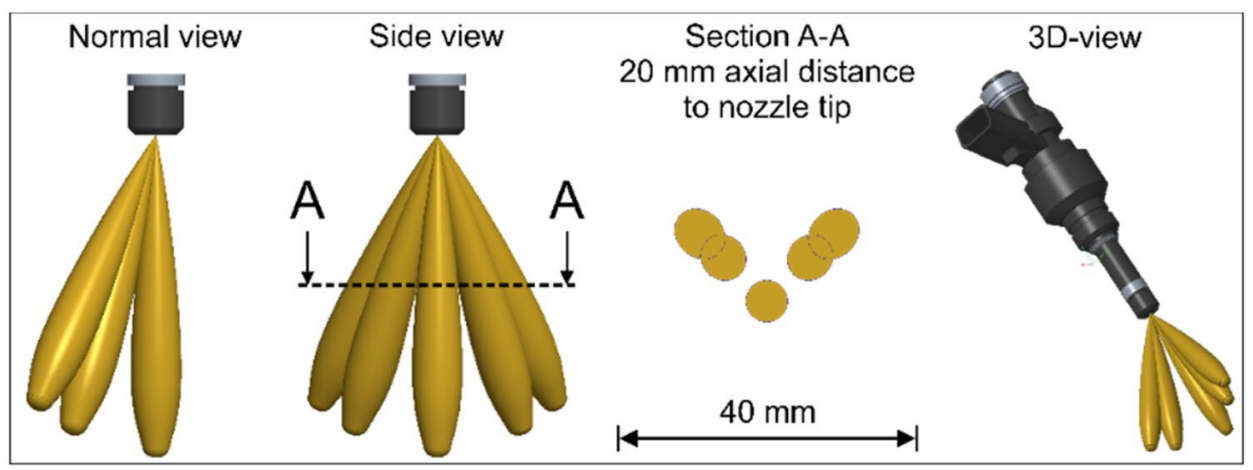

is $16 \mathrm{MPa}$ and the injection duration is $1.8 \mathrm{~ms}$. The section $\mathrm{A}-\mathrm{A}$, which is located $20 \mathrm{~mm}$ beyond the nozzle, presents the spray interaction with the neighboring spray plumes. The center plume is separated from the remaining plumes, which allows unrestricted optical access. This central plume shows less jet-to-jet interactions, so that it is analyzed in the framework of this study. The operating conditions of the constant volume chamber for the spray
Table 1 Operating conditions of the CVC chamber

\begin{tabular}{lll}
\hline Property & Unit & \\
\hline Ambient gas & - & Air \\
Ambient pressure & $\mathrm{MPa}$ & 0.2 \\
Ambient gas temperature & $\mathrm{K}$ & 293 \\
Injection pressure & $\mathrm{MPa}$ & 16 \\
Fuel temperature & $\mathrm{K}$ & 293
\end{tabular}


measurements performed in this study are displayed in Table 1.

\subsection{PDA-measurement setup}

The PDS-measured SMDs are compared to point-wise PDAmeasurements. For this purpose, the injector is transferred to a PDA-equipped injection chamber. The PDA system used is a FiberPDA (Dantec Dynamics A/S) combined with an Innova 305C laser (Coherent Inc.). The four laser beams were overlapped in an intersection volume by a transmitter optic using a $310 \mathrm{~mm}$ collimating lens. The resulting probe volume has a length of $468 \mu \mathrm{m}$ and a diameter of $45 \mu \mathrm{m}$. The probe volume contains 15 fringes with a corresponding fringe spacing of $2.67 \mu \mathrm{m}$. This configuration enables a droplet size detection up to $60 \mu \mathrm{m}$. The probe volume is positioned within the fuel spray using a 3-D linear stage. The signal bursts are detected with an optical receiver with a $310 \mathrm{~mm}$ collimating lens and an aperture for small particles. The aperture used limits the effective length of the measurement volume to $50 \mu \mathrm{m}$. Signal detection is performed under the Brewster angle of $70^{\circ}$. This detection setup is less sensitive to changes in the refractive index due to different fuels and varying droplet temperatures.

The SMD is determined at various positions within the fuel spray. A reliable droplet determination with the LIF/Mie technique or PDA is not possible near the nozzle $(<10 \mathrm{~mm})$ due to the presence of non- spherical droplets and ligaments, which are caused by droplet deformation, secondary break-up and coalescence. To be able to investigate a large radial area, droplets with a distance of $40 \mathrm{~mm}$ to the nozzle and more are taken into account for the validation. For each measurement position, 120 injections are evaluated, which results in about 30,000-50,000 validated droplets per position.

\subsection{Numerical simulation}

A simulation of evaporating single droplets was conducted in Matlab ${ }^{\circledR}$. It is employed for the assessment of the experimental results and especially for an uncertainty analysis of the PDS-technique. The applied 1-D diffusion limited model (DLM, convective, non-ideal) considers the internal heat and mass diffusion, i.e. the temporal and spatial gradients of the properties of the liquid mixture (Keller et al. 2013). The model describes the diffusive transport but neglects convection inside the droplet (internal circulations), which is usually covered by "effective diffusivity models" (EDM). The other extreme is the "rapid-mixing model" (RMM) assuming infinitely fast diffusion. The "true" evaporation characteristic is expected between the two extreme cases of DLM and RMM (Wilms 2005). Under the present injection conditions, the results of the RMM and DLM are very similar and are given in the appendix. Consequently, only results of the DLM are given in the results section of the paper for brevity.

The model uses an adaptive time step while holding the change in temperature and mass constant. The thickness of each shell is kept constant at around $1 \mu \mathrm{m}$. The number of shells decreases with the size of the droplet as evaporation occurs. The vapor-liquid equilibrium is calculated using a non-ideal $\gamma-\varphi$ model assuming thermodynamic equilibrium at the droplet surface. In this model, $\gamma$ is the activity coefficient and $\varphi$ is the liquid fugacity coefficient for pure components. The activity coefficients are calculated using the UNIFAC (universal quasi-chemical functional group activity coefficients) group contribution method. Consequently, this model considers effects of demixing of the fuel components and preferential evaporation on the droplet composition, which is an important information for discussion of the uncertainty of the measurement technique in case of evaporation. This is especially important as preferential evaporation may occur for ethanol-isooctane blends (Bader et al. 2013). Convection in the gas phase is considered by the Frossling correlations of the Nusselt number and Sherwood number (Abramzon and Sirignano 1989). The droplets are described by a constant velocity of $20 \mathrm{~m} / \mathrm{s}$, which is a typical average value for DISI conditions in the studied spray zones (see, e.g., reference (Heldmann et al. 2015) for this specific injector). This means that effects of air drag and droplet deformation are not considered. The numerical boundary conditions match the real boundary conditions in the injection chamber (see Table 1), except of the definition of the ambient gas for which nitrogen is applied instead of air.

It should be noted that this model describes only isolated single droplets. This is of course a simplification since the evaporation in a dense spray is affected by the interaction of neighboring droplets and vapor. Consequently, the predicted evaporation rate of the isolated droplet is larger than in the dense spray. Thus, the simulation is a worst-case scenario and the resulting dye concentration in the droplet would be over-estimated for a given droplet lifetime. The model used thus gives an upper bound for the uncertainty.

\subsection{Applied fuels and tracers}

The sooting tendency of commercial gasoline is mainly driven by its aromatic components like toluene, benzene or xylene etc., which match up to $35 \mathrm{vol} \%$. Toluene is known as octane-number enhancer in gasoline with concentrations of up to $15 \mathrm{vol} . \%$ (Burri et al. 2004). Toluene is an aromatic hydrocarbon and mixtures with isooctane and $\mathrm{n}$-heptane lead to a similar sooting behavior as for commercial gasoline (Choi et al. 2011). In accordance with our previous studies (Koegl et al. 2018a,2019d; Storch et al. 2016c,d) and to avoid compositional variations of gasoline, the two-component surrogate fuel Toliso (65 vol.\% isooctane, 35 vol. $\%$ 
toluene) was used in this work. Toliso has similar thermophysical properties as multi-component gasoline. The effect of biofuel admixture was considered by blending Toliso with 20 vol.\% of ethanol (E20). The chemical and physical properties of the investigated fuels for various ambient conditions are shown in Table 2.

While it may be assumed that the fluorescence tracer Nile red $\left(\mathrm{C}_{20} \mathrm{H}_{18} \mathrm{~N}_{2} \mathrm{O}_{2}\right.$, Sigma Aldrich) added does not significantly change the fluid properties of the fuels, the different fuels may affect the fluorescence of the dye. To achieve a good signal to noise ratio, the fuel for the droplet investigations was doped with $100 \mathrm{mg} / \mathrm{l}$ Nile red. The dye nile red belongs to the group of fluorophores and its aromatic ring structure contains polar substituents. These properties lead to a high sensitivity to the chemical and physical environment of surrounding solvent molecules (Kalathimekkad et al. 2015). Consequently, the polarity of the fuel (see Table 2) will affect the fluorescence and the LIF/ Mie ratio, which could potentially influence the accuracy of the technique.

The fuel properties of Toliso (or isooctane and toluene, respectively) match those of gasoline quite well; especially viscosity, surface tension and heat of vaporization are very similar. As mentioned above, ethanol addition will lead to an increase of viscosity and surface tension, which could affect atomization. Thus, the fuel dependent Weber numbers We and Reynolds numbers Re are provided to estimate the resulting SMD values according to the model of Hiroyasu and Arai (1990). The Weber and Reynolds numbers are defined as follows:

$\operatorname{Re}=\frac{d_{\text {Nozzle }} \times \rho_{\mathrm{F}} \times u_{\text {Nozzle }}}{\eta_{\mathrm{F}}}$

$\mathrm{We}=\frac{d_{\text {Nozzle }} \times \rho_{\mathrm{F}} \times u_{\text {Nozzle }}^{2}}{\sigma_{\mathrm{F}}}$,

where $d_{\text {Nozzle }}$ is the nozzle diameter, and $u_{\text {Nozzle }}$ is the initial velocity at the nozzle. The relevant fuel properties are the fuel density $\rho_{\mathrm{F}}$, the surface tension $\sigma_{\mathrm{F}}$ and the dynamic viscosity $\eta_{\mathrm{F}}$. The resulting SMD can be estimated according to the model of Hiroyasu and Arai (1990):

$\mathrm{SMD}=4.12 \mathrm{Re}^{0.12} \mathrm{We}^{-0.75}\left(\frac{\eta_{\mathrm{F}}}{\eta_{\mathrm{A}}}\right)^{0.54}\left(\frac{\rho_{\mathrm{F}}}{\rho_{\mathrm{A}}}\right)^{0.18} \times d_{\text {Nozzle }}$.

The included properties of the ambient gas are the density $\rho_{\mathrm{A}}$ and the dynamic viscosity $\eta_{\mathrm{A}}$.

The Reynolds and Weber numbers of the pure fuels at ambient conditions ( $293 \mathrm{~K}, 0.1 \mathrm{MPa}$ ) with a nozzle diameter of $168 \mu \mathrm{m}$ and an estimated initial velocity of $120 \mathrm{~m} / \mathrm{s}$ at the nozzle [derived out of (Storch et al. 2016c) at similar operating conditions] are given in Table 3.

The predicted SMDs according to the model of Hiroyasu and Arai are shown in Table 4 for the pure fuels and the investigated fuel blends (using mass-weighted averages of fuel properties). The estimation was deduced for the properties of the fuel at $0.1 \mathrm{MPa}$ (Table 3 ) and the properties of air at $0.2 \mathrm{MPa}\left(\eta_{\mathrm{A}}=18,29 \mu \mathrm{Pa} \cdot \mathrm{s}, \rho_{\mathrm{A}}=3,56 \mathrm{~kg} / \mathrm{m}^{3}\right.$; taken from Ref. VDI-Gesellschaft Verfahrenstechnik und Chemieingenieurwese (2013).

The predicted SMDs show the largest droplet size for ethanol followed by toluene and isooctane. For E20, slightly larger droplet sizes are predicted in comparison to Toliso. However, evaporation effects are not considered in these calculations. Ethanol, due to its lower evaporation temperature in comparison to isooctane and toluene, should evaporate faster. However, ethanol shows the highest evaporation enthalpy of all investigated fuels. This fact could lead to a strong cooling effect of the ambient gas, which could result

Table 3 Reynolds and Weber numbers of the investigated fuels, $0.1 \mathrm{MPa}, 293 \mathrm{~K}$

\begin{tabular}{llll}
\hline $\begin{array}{l}\text { Non-dimensional } \\
\text { number }\end{array}$ & Isooctane & Toluene & Ethanol \\
\hline $\mathrm{Re}$ & 27,765 & 29,879 & 13,910 \\
$\mathrm{We}$ & 88,790 & 73,849 & 85,320 \\
\hline
\end{tabular}

Table 2 Physical and chemical properties of the investigated fuels (Dean 1999; Bronkhorst 2019; GmbH et al. 2011; Wang et al. 2006; Luning Prak et al. 2014; Reichardt and Welton 2010; Schirmer 1990)

\begin{tabular}{llllll}
\hline Property & Unit & Isooctane & Toluene & Ethanol & Gasoline \\
\hline H/C-ratio & - & 2.25 & 1.14 & 3 & $\sim 1.92$ \\
Boiling point @ 0.1 MPa & $\mathrm{K}$ & 372 & 383 & 351 & $298-483$ \\
Density @ 293 K, 0.1 MPa & $\mathrm{g} / \mathrm{cm}^{3}$ & 0.69 & 0.87 & 0.79 & $0.720-0.775$ \\
Dynamic viscosity @ 0.1 MPa, 293 K & $\mathrm{mPa} \mathrm{s}$ & 0.501 & 0.587 & 1.145 & $\sim 0.6$ \\
Surface tension @ 293 K & $\mathrm{N} / \mathrm{m}$ & 0.0188 & 0.0285 & 0.0224 & $\sim 0.0216$ \\
Heat of vaporization @ 293 K & $\mathrm{kJ} / \mathrm{kg}$ & 305.4 & 409.3 & 938.2 & $380-500$ \\
Stoichiometric air-fuel ratio & $\mathrm{kg} / \mathrm{kg}$ & 15.2 & 13.4 & 9.0 & $\sim 14.7$ \\
Lower Heating Value & $\mathrm{MJ} / \mathrm{kg}$ & 44.6 & 40.6 & 26.8 & $40.1-41.6$ \\
Polarity & - & -0.4 & 2.3 & 5.2 & - \\
\hline
\end{tabular}


Table 4 Predicted SMDs according to the model of Hiroyasu and Arai, 0.1 MPa, $293 \mathrm{~K}$

\begin{tabular}{lllllll}
\hline & Unit & Isooctane & Toluene & Ethanol & Toliso & E20 \\
\hline SMD & $\mu \mathrm{m}$ & 7.08 & 9.32 & 10.75 & 7.86 & 8.44
\end{tabular}

in a reduced evaporation rate of the fuel droplets in these areas.

\section{Results}

In the first part of this section, the spray structure is analyzed using the SLIPI LIF/Mie technique. Afterwards, the LIF/Mie ratio is calibrated with suitable calibration curves using a droplet generator (Koegl et al. 2019c). The fueldependent spray shape is analyzed in terms of the cyclic variation. Finally, the calibrated droplet size distributions are compared to point-wise PDA measurements. A numerical simulation of evaporating single droplets is conducted for a discussion of different sources of error of the PDS-technique under conditions with low evaporation rate.

\subsection{Spray structure analysis using single-shot LIF and Mie images}

Single-shot images of the LIF- and the Mie-signals as well as the corresponding LIF/Mie-ratio of Toliso are shown in Fig. 3. The acquisition point in time is $1600 \mu$ s after electric
Fig. 3 Single-shot images of the LIF- and Mie-signals and the corresponding LIF/Mie-ratio of Toliso, $1600 \mu \mathrm{s}$ aESOI

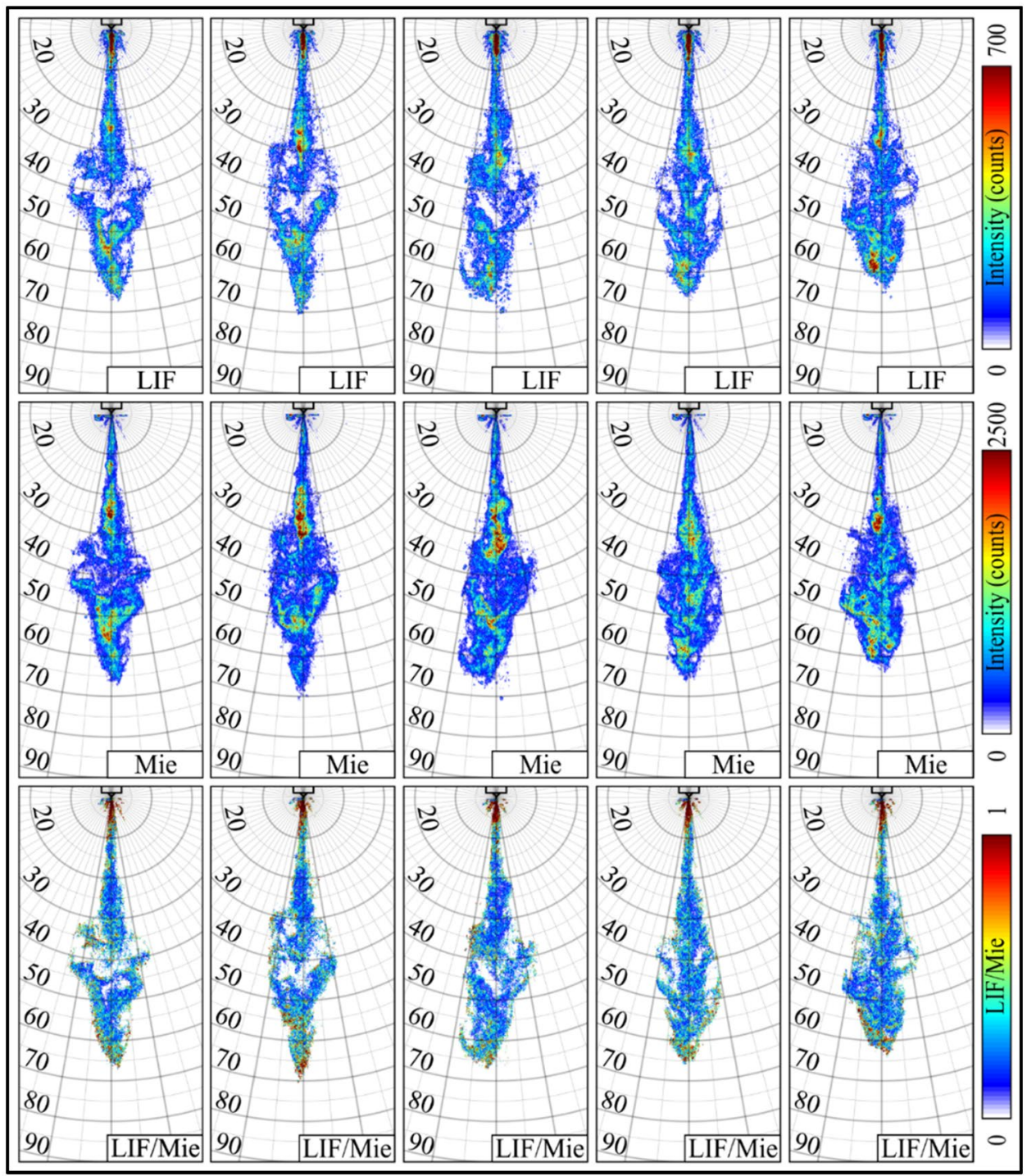


start of injection (aESOI), which is relatively late during the injection event.

The single-shot images enable a visualization of the turbulent spray structure, which is not possible with average images. The modulated laser light sheet enters the injection chamber from the left side and illuminates the central separated spray plume of the DISI-injector (compare Fig. 2). A comparison between the LIF- and the Mie-signals reveals that local high intensities are present in both channels. The corresponding LIF/Mie-ratio is largest at the spray front and at the radial spray edges, which corresponds to large droplet sizes. Aerodynamic forces are large at the spray front leading to a deceleration of the spray and a collision of fuel droplets and coalescence. This results in large droplets at the spray front, which are still present at late observation times. Inside the spray there are areas with low droplet densities ("cavities"), which are formed by the pulsating flow of the injector and the locally present large vortices. These areas are indicated by low LIF/Mie-ratios in their respective centers due to the presence of very small droplets. In general, these five images characterize cyclic variations of the spray structure very well. It is also important to note that the above-mentioned cavities appear very often at very similar positions in the sprays. This indicates that the turbulent spray motion is reproducible up to a certain point.

\subsection{Calibration of the LIF/Mie ratio}

The SMD distribution can be deduced from the LIF/Mie ratio measurements with an adequate calibration like the use of PDA data (Koegl et al. 2019a; Gal et al. 1999) or single droplet LIF/Mie data of a droplet generator (Domann and Hardalupas 2001b; Koegl et al. 2018b; Mishra et al. 2019). Here, the LIF/Mie ratios of Toliso and E20 sprays are quantified with single droplet calibration curves recorded by using a microscopic setup [for details see (Koegl et al. 2019c)]. Monodisperse droplets were studied in a diameter range of 20-50 $\mu \mathrm{m}$ using a droplet generator (type 1530, MSP Corp., Shoreview, USA). This selected diameter range is relevant for DISI-sprays. The lower adjusted droplet size is limited by the droplet generator. The LIF and Mie measurements were conducted approximately 3-7 $\mathrm{mm}$ below the exit of the droplet generator, which depends on the respective droplet size.

The individual droplets were evaluated regarding their sphericity, which is defined as the ratio of the minimum and maximum distance of the individual droplet. Other criteria were their location in the measurement region, and distance to neighboring droplets to clearly separate droplets from each other in the droplet chain. Only droplets with a sphericity between 1.0 and 1.2 were considered for further evaluation.
The calibration curves for the two investigated fuel mixtures with their uncertainty (standard deviation) of the micrometric droplets are shown in Fig. 4. Additionally, bin-wise averaged LIF and Mie-signals of the droplets are provided in the bottom rows $\left(d_{\text {droplet }} \pm 0.25 \mathrm{~mm}\right)$. In total, more than 30,000 single droplets were processed for each fuel. The fit curves show a similar behavior for both investigated fuels, while the uncertainty is slightly larger for Toliso in comparison to E20. For instance, the uncertainty of a $30 \mu \mathrm{m}$ droplet is $\pm 20 \%$ for Toliso and $\pm 16 \%$ for E20.

The LIF/Mie ratios for both investigated fuels can be described by the following equations:

$I_{\text {LIF/Mie_Toliso }}=0.0092 \times d_{\text {droplet }}^{1.14}$

$I_{\text {LIF/Mie_E20 }}=0.0087 \times d_{\text {droplet }}^{1.14}$.

Both fit curves show a very similar function with the same exponent and slightly different pre-exponential factors (Gal et al. 1999; Domann and Hardalupas 2003).

The microscopic LIF and Mie signals of single droplets will be discussed in brief. The bin-wise averaged droplets show a signal throughout the complete droplet. A larger LIF intensity can be observed in the center of the droplet. In the LIF-images, two bright spots at the left and two spots at the right side are generated. The focusing of the laser rays toward the right half side creates spots in the region opposite to the laser side. This is a dominant effect for small droplets (about 10-50 $\mu \mathrm{m}$ ) and a weak absorption coefficient (Frackowiak and Tropea 2010b). Internal reflections create an illumination in the left part of the droplet. Details can be found in reference (Frackowiak and Tropea 2010b), in which a fluorescence model based on Lorenz-Mie theory and a ray-tracing method were utilized. In case of larger laser fluences (which is typically true for pulsed laser operation), MDRs (or cavity mode effects) occur inside the droplets. These ring-shaped structures occur at the outer region of the spherical droplets. These effects disappear when the droplets are slightly deformed. In general, the MDRs do not appear very pronounced and only few images show MDRs at all. Obviously, the MDR effect is less pronounced for the selected laser fluence, dye and droplet size range as well as dye concentration in comparison to droplet studies with pyrromethene 5978C9 [see e.g. (Palmer et al. 2018)]. Slightly more distinct MDR-effects were observed for E20 in comparison to the base fuel Toliso (see Fig. 4, e.g. for $50 \mu \mathrm{m}$ diameter). According to the literature, MDR-effects would cause a LIF exponent greater than three [in this study they were 3.03 (Toliso) and 3.34 (E20), respectively] and a Mie exponent greater than two (Gal et al. 1999) [here: 1,87 and 2.02 (E20), respectively; for details see Koegl et al. 
Fig. 4 Calibration curve of the experimental data using a droplet generator for Toliso and E20 (top). Corresponding bin-wise averaged LIFsignals of the droplets (bottom, $d_{\text {droplet }} \pm 0.25 \mu \mathrm{m}$, the intensity was normalized to the respective maximum signal to ensure visibility); Data were extracted from Koegl et al. (2019c)
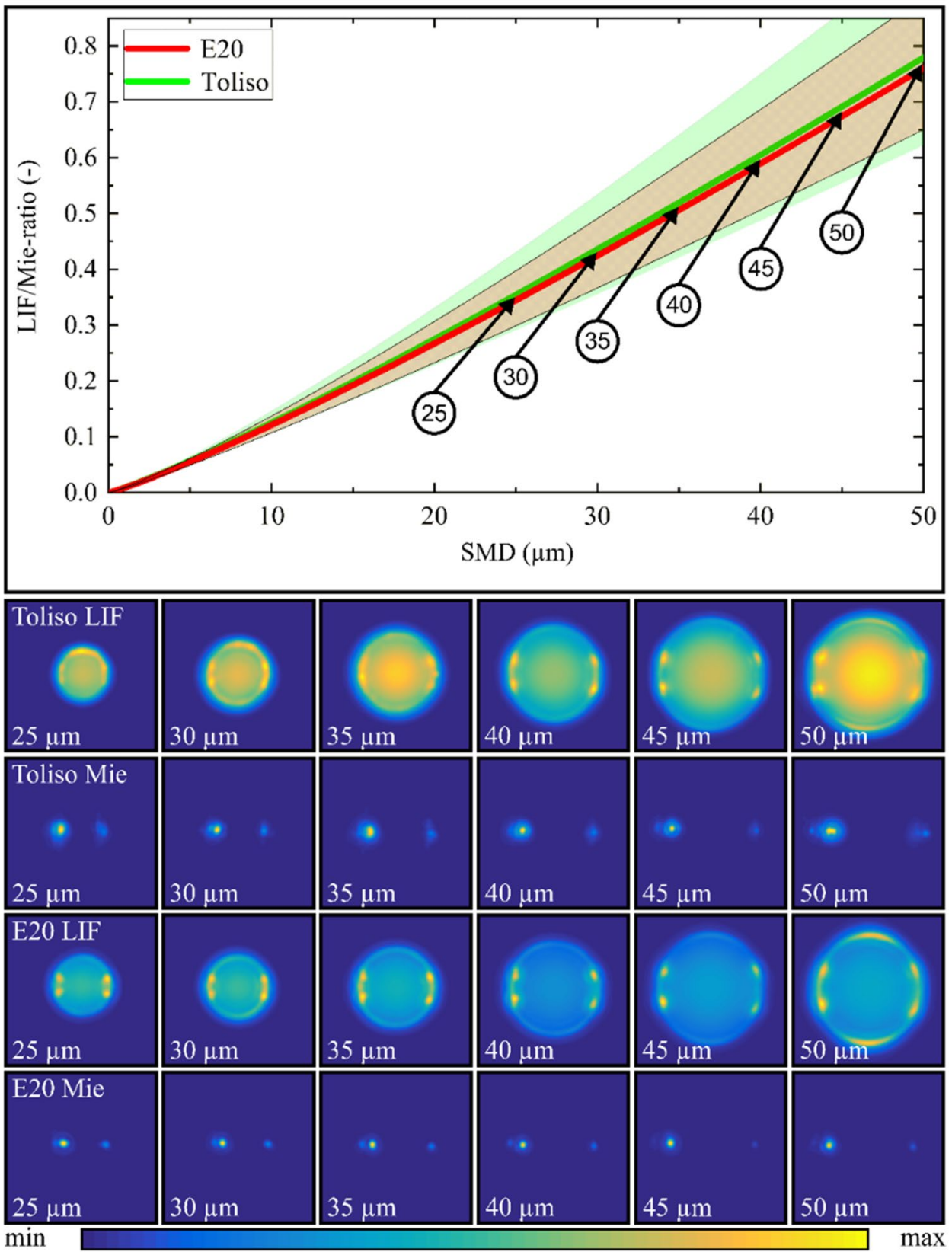

(2019c)]. The exponents of the resulting LIF/Mie ratios of the investigated fuels are both 1.14 and the presence of MDRs consequently does not show a significant impact on the LIF/Mie ratio.

Besides the uncertainties of the calibration data (see Fig. 4), further uncertainties have to be considered in the spray measurements. In principle, the LIF/Mie ratio does not depend on the laser fluence in the investigated range. Both the LIF and Mie signals showed a linear increase with larger laser fluence (up to $90 \mathrm{~mJ} / \mathrm{cm}^{2}$ ) and no saturation effects were observed (Koegl et al. 2019c). The laser fluence of the SLIPI light sheet is $48 \mathrm{~mJ} / \mathrm{cm}^{2}$ and it is thus considered uncritical regarding saturation of fluorescence and dissociation of the dye. A change of the liquid temperature as well as a change of the tracer concentration due to droplet heating and evaporation can lead to further uncertainties. While the change of the tracer concentration results in a nearly proportional variation of the LIF/Mie ratio, the temperature dependence strongly depends on the tracer-solvent combination. An earlier study revealed that the PDS technique based on Nile red dissolved in E20 shows a low temperature dependency at moderate temperatures (Koegl et al. 2019b). For example, a variation of the droplet temperature from 263 to $293 \mathrm{~K}$ leads to a variation of the LIF/ Mie ratio of $9 \%$ for a droplet size of $30 \mu \mathrm{m}$ (Koegl et al. 2019c). At higher temperatures, the LIF/Mie-ratio increases 
due to temperature-dependent absorption and emission behavior of the dye for a constant dye concentration. For example, the LIF/Mie-ratio is doubled for an increase from 293 to $323 \mathrm{~K}$ and a droplet size of $30 \mu \mathrm{m}(100 \mathrm{mg} / \mathrm{l} \mathrm{Nile} \mathrm{red}$ in E20). Temperature and dye concentration effects on the PDS-measurement uncertainty during evaporation will be analyzed in a numerical study in Sect. 3.5 for the studied injection conditions.

A change in liquid composition (i.e. the toliso/ethanol ratio) due to preferential evaporation would change the LIFintensity as well. However, as the LIF/Mie-ratio calibration curves are very similar for toliso and E20 (see Fig. 4), we believe that this effect is negligible at the present conditions.

\subsection{Spray structure analysis using PDS}

The quantified LIF/Mie ratios of the Toliso and E20 in terms of the SMD are shown in Fig. 5 (single shot images) and the corresponding average images and coefficient of variation (COV) images are exhibited in Figs. 6 and 7.

In the single shot images, large SMDs (about $45 \mu \mathrm{m}$ ) are present at the spray front and very often in the outer radial spray regions. Larger SMDs appear also close to the nozzle. There are no significant differences between Toliso and E20 in the range of measured droplet sizes.

The average images and the COV are calculated from 100 single images. The axial penetration depth is very similar for both fuels. The droplet sizes are very similar for the two fuels at $800 \mu$ s. E20 shows a slightly larger radial spray width and slightly larger droplet sizes at late observation times $(2000 \mu \mathrm{s}$ aESOI). The largest droplet sizes $(\geq 30 \mu \mathrm{m})$ are located at the spray front and the adjacent radial spray edges. The droplet sizes in the spray center are in the range of 18-26 $\mu \mathrm{m}$. These regions are relatively dilute due to the pulsating spray and appearing vortex cores (see single shot images in Fig. 5), which are created by the pulsating nozzle flow. These vortices are present in many single shot images (see Figs. 3 and 5). The spray appears slightly asymmetric, which can be assigned to the shot-to-shot variations in the spray shape, which show that the bend angle varies between the injections. Very often, the sprays are more bended to the "left" side (see Figs. 3 and 5), probably due to interactions with neighboring jets. Similar effects were also reported earlier for this injector but for another fuel (pure ethanol), see Mishra et al. (2019). In principle, both fuels show an increase of average droplet sizes with time, which needs further discussion.

The coefficient of variation $(\mathrm{COV}$, which is the ratio of the standard deviation and the average value) of the SMD is used as an indicator of the cyclic variations of the highly turbulent spray. The COV does not exhibit significant changes with the observation time, see Fig. 7.

In general, the COV shows its smallest values in the spray center (0.8-1.5), since liquid fuel is always present in these regions. The biggest fluctuations of Toliso and E20 sprays occur at the spray front and radial boundaries (with COV
Fig. 5 Single shot SMD images of Toliso (top) and E20 (bottom row), for $1200 \mu \mathrm{s}$ aESOI

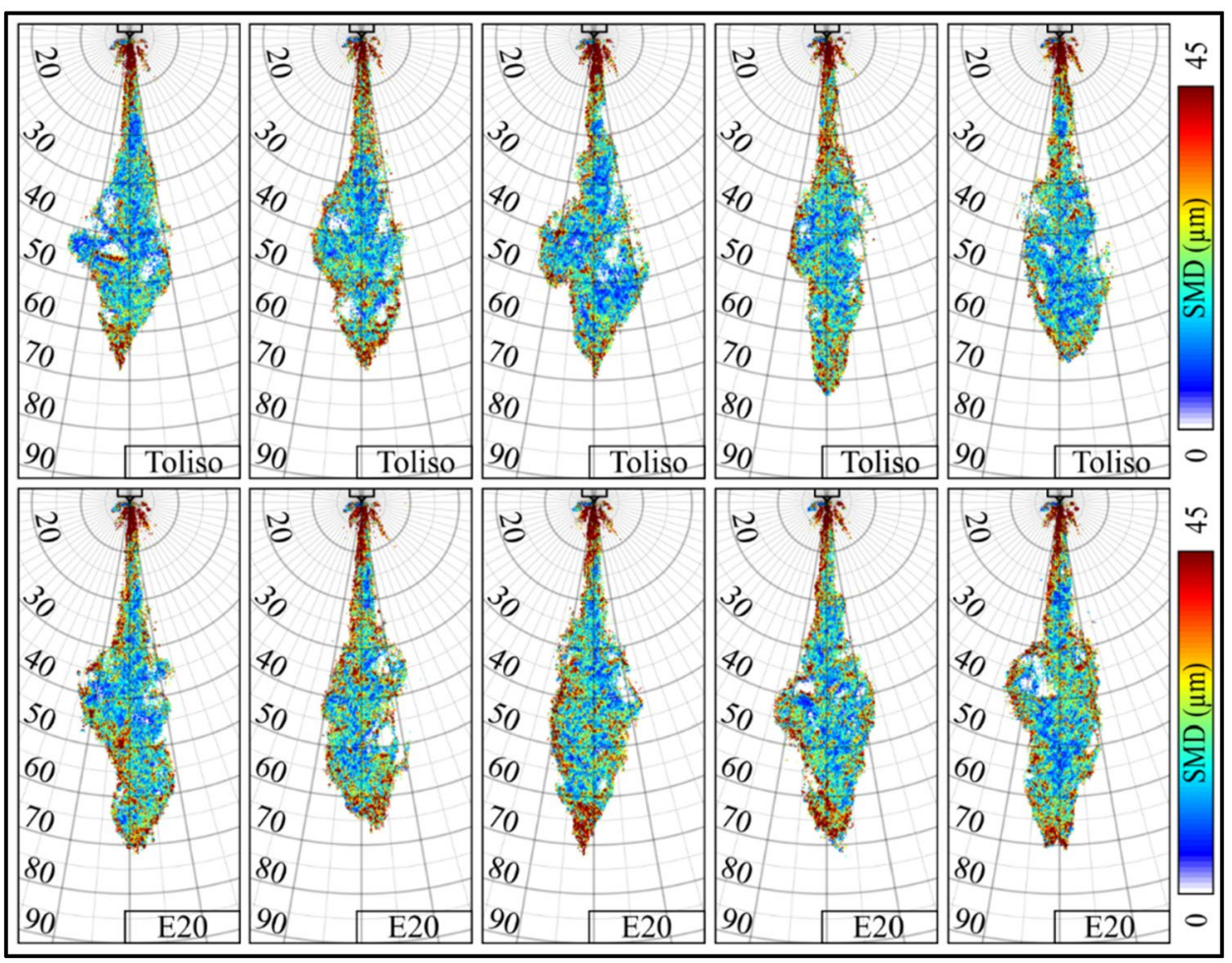


Fig.6 Quantified droplet size distribution SMD of Toliso (top) and E20 (bottom), at various times aESOI

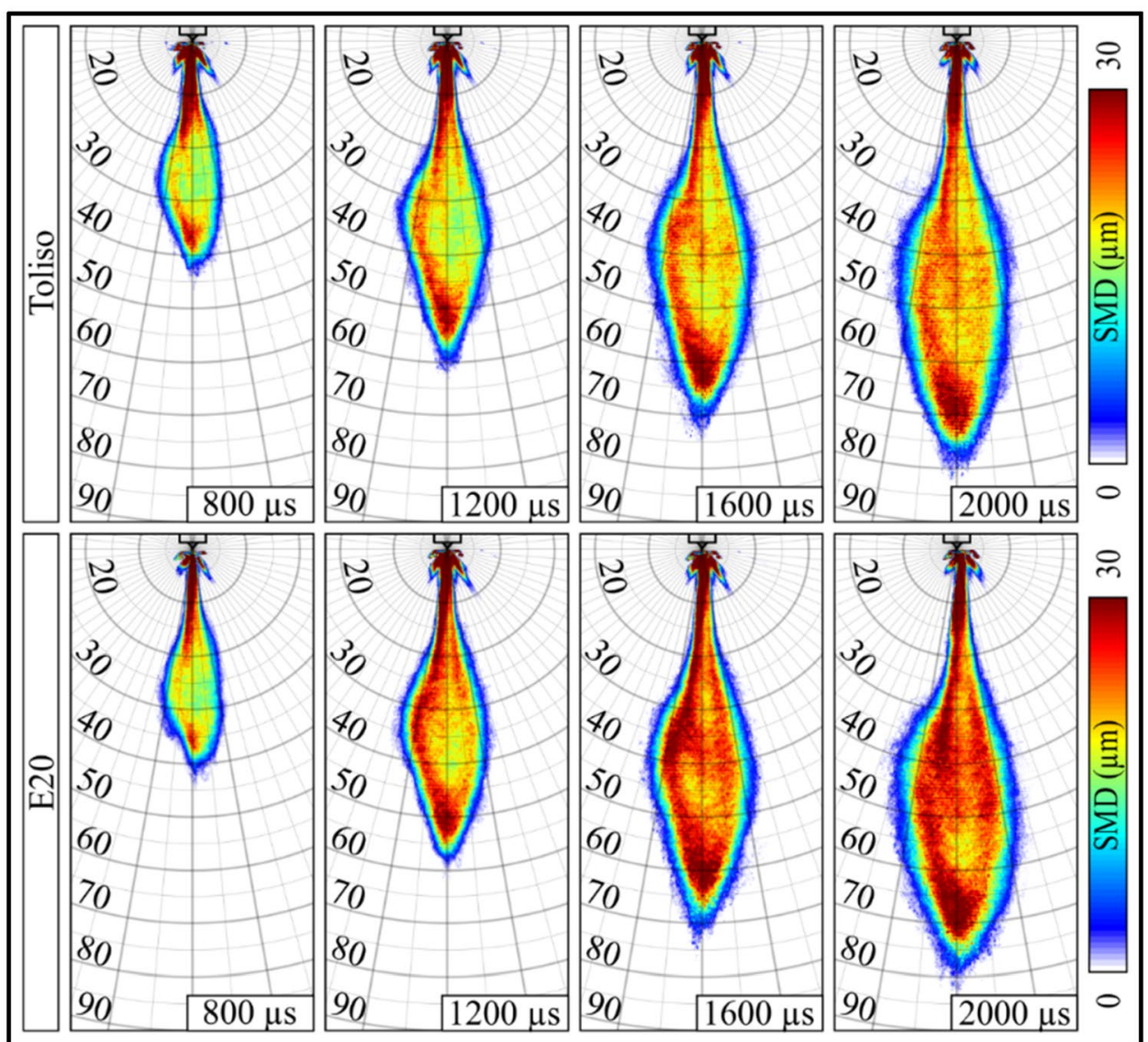

values of up to 5), which are driven by the shot-to-shot variation of the axial and radial spray propagation. This strong variation can also be seen in the single shot images (see Fig. 5). The coefficient of variation shows no significant differences between E20 and Toliso.

\subsection{Comparison of PDS-SMD with PDA-data}

In this section, the SMDs derived from the SLIPI LIF/Miemeasurements are compared to point-wise PDA measurements. The LIF/Mie-ratio images and the corresponding PDA-measurement points for various observation times are shown in Fig. 8. The PDA data itself exhibit a similar spray structure in terms of SMD for Toliso and E20. At early observation times (1200 $\mu$ s aESOI), the LIF/Mie SMDs show good agreement with the PDA-measurements. At later points in time, the PDA measured SMDs are smaller in comparison to the droplet sizes extracted from the LIF/ Mie ratio, which increase with time.

After $1600 \mu \mathrm{s}$, the overall droplet sizes determined by SLIPI LIF/Mie start to increase for both fuels, probably due to the progressing evaporation. This effect was not observed in earlier studies executed with ethanol and the dye Eosin Y (Koegl et al. 2019a; Mishra et al. 2019). Ethanol exhibits a lower evaporation rate, as its evaporation enthalpy is more than twice as high than those of Toliso and E20. This leads to a significantly lower dye enrichment for Ethanol in comparison to Toliso and E20 and finally to larger measurement uncertainties in the case of Toliso and E20. This aspect is further discussed in the subsequent paragraph.

In order to compare the two different fuels in detail, the LIF/Mie-ratio and the corresponding point wise PDA measurements are shown in Fig. 9 for various axial distances from the nozzle. These planes were chosen for comparison as here a relatively large number of droplets were evaluated in both PDA and PDS measurements especially at early points in time. The positions represent the main spray and the spray front at $1200 \mu$ s and $2000 \mu \mathrm{s}$ aESOI. At $1200 \mu \mathrm{s}$, the PDSmeasured SMDs are very similar for both fuels. At $40 \mathrm{~mm}$ (top left image in Fig. 9), the PDS-SMDs show a doublepeak with variations for both fuels from about $15 \mu \mathrm{m}$ in the center to $27 \mu \mathrm{m}$ (at the left boundary). Similar SMDs were observed for both fuels at the spray front $(55 \mathrm{~mm})$ as well. At $2000 \mu \mathrm{s}$ aESOI (top right in Fig. 9), the PDS-measured SMDs show larger droplets, which are on overage $22 \mu \mathrm{m}$ in the spray center and $30 \mu \mathrm{m}$ at the left boundary. In general, the spray plume of E20 is slightly wider in comparison to Toliso especially at $2000 \mu$ s. The droplet sizes derived from PDS show a slightly larger SMD for E20 in comparison to Toliso. 
Fig. 7 Coefficient of variation (COV) of SMD for Toliso (top) and E20 (bottom), at various times aESOI

Fig. 8 SMD measured by SLIPI LIF/Mie overlaid with PDAdata for Toliso (top) and E20 (bottom) at various points in time aESOI
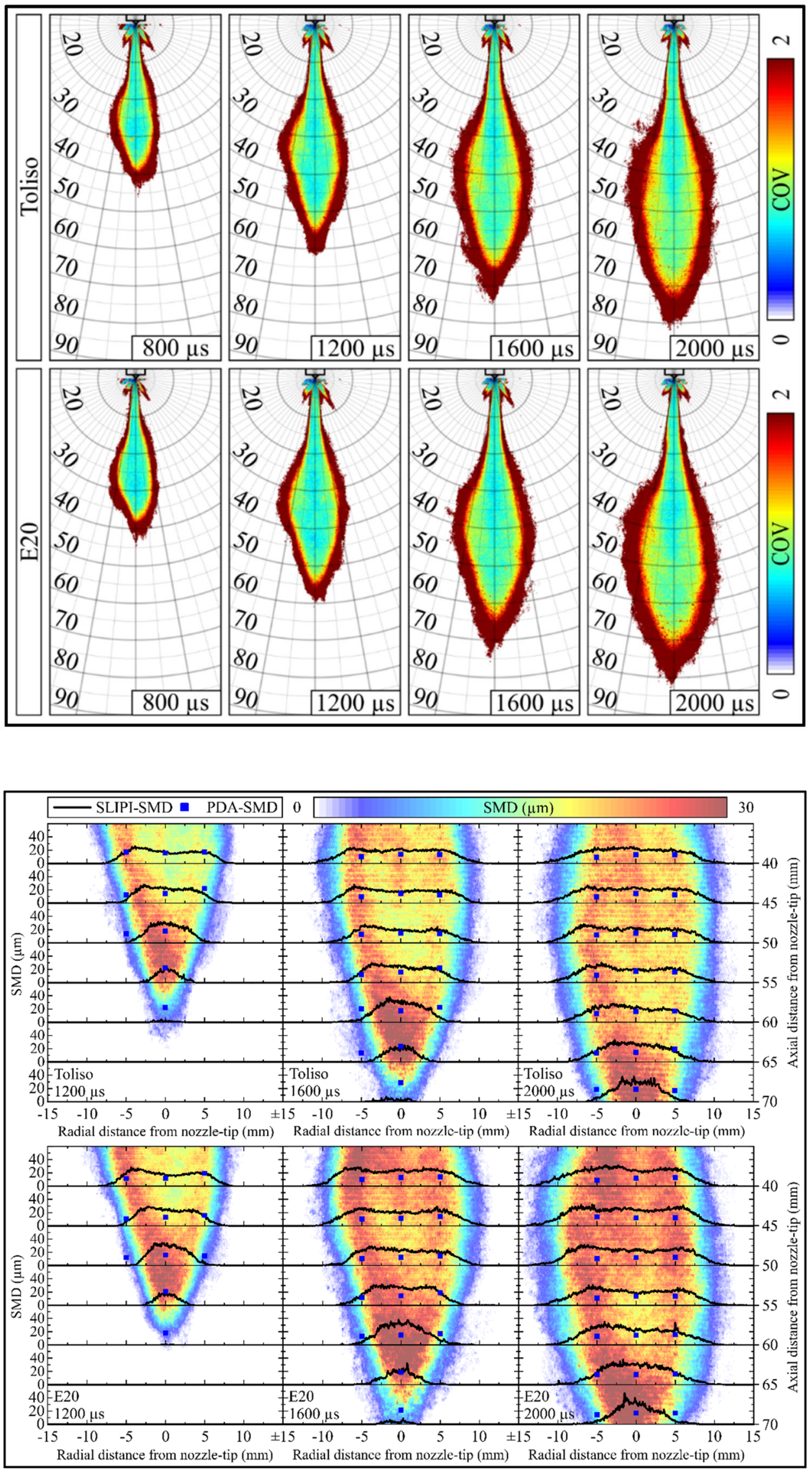


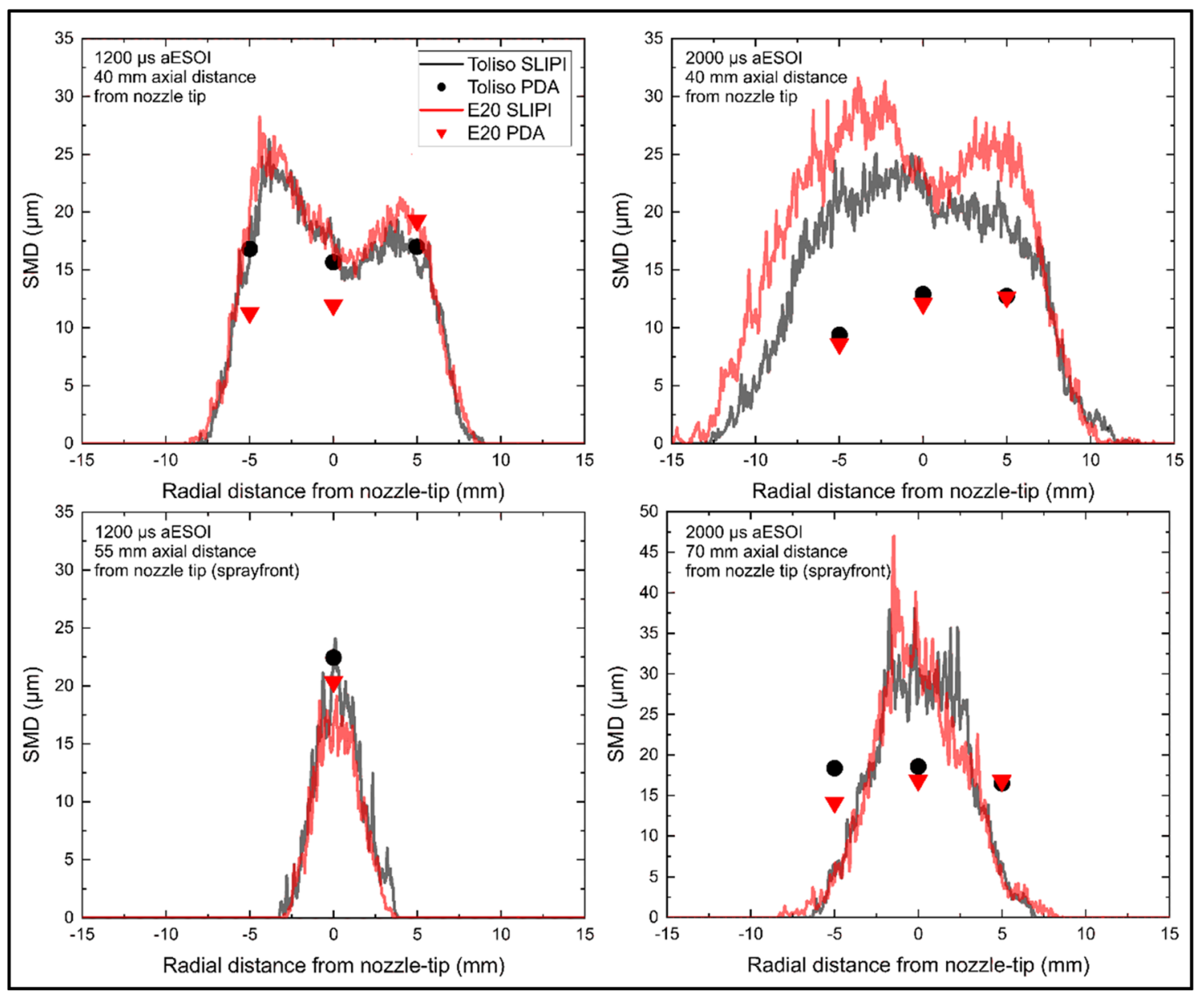

Fig. 9 SMD deduced from calibrated SLIPI LIF/Mie-ratio (curves) and PDA data (points) of Toliso and E20 at $1200 \mu$ s and $2000 \mu \mathrm{s}$ aESOI for various axial distances to the nozzle. The top line repre-

The position $55 \mathrm{~mm}$ represents the spray front with SMDs from about $15-23 \mu \mathrm{m}$ at $1200 \mu \mathrm{s}$ aESOI. At $2000 \mu \mathrm{s}$, the spray front is at an axial distance of $70 \mathrm{~mm}$ from the nozzle at which the SMDs increase between $25 \mu \mathrm{m}$ to $45 \mu \mathrm{m}$. At $2000 \mu \mathrm{s}$, the PDA-measured SMDs are smaller than at $1200 \mu \mathrm{s}$.

For comparison with PDA at discrete positions, the PDSSMD values are averaged from 11 pixels in the respective line corresponding to about $400 \mu \mathrm{m}$. This averaging compensates the fluctuations in the PDS-SMD images for a fairer comparison. The PDA measurements showed a similar SMD for both fuels for all investigated observation times. The SMD at early observation points $(1200 \mu \mathrm{s}$ aESOI) is in a good agreement with the PDS-SMDs. The offset between PDA and PDS is relatively small for Toliso at $1200 \mu$ s and $40 \mathrm{~mm}$ : it is $0.0 \%$ (at $R=-5 \mathrm{~mm}), 11.3 \%(R=0 \mathrm{~mm}$ ) and $9.5 \%(R=5 \mathrm{~mm})$. Even at the spray front $(55 \mathrm{~mm})$, the difference is just $3.5 \%$. For E20, the offset between PDA and PDS is $25.2 \%$ at $70 \mathrm{~mm}$. At $40 \mathrm{~mm}$, the offset is $29.5 \%$ $(R=0 \mathrm{~mm}), 1.3 \%(R=5 \mathrm{~mm})$ and $44.2 \%(R=-5 \mathrm{~mm})$. sents the main spray region while the bottom line depicts the spray front. Note the changed SMD-range of the $y$ axis

Probably, this large deviation at the left radial spray boundary is due to slight variations in the measurement position between PDA and PDS, which can hardly be quantified.

At $2000 \mu$ s the SMDs of Toliso and E20 derived from PDA are lower by about $50 \%$ on average in comparison to the PDSSMD. Most probably, this behavior is mainly caused by the tracer enrichment due to the partially evaporating droplets. This effect will be discussed in Sect. 3.4. It should be also noted that the uncertainty of PDA measurements is usually in the range of at least $4 \%$ in spray regions without significant multiple scattering (i.e. dilute sprays) (Jermy and Greenhalgh 2000).

For a more detailed view on fuel-dependent spray behavior, normalized histograms of the PDA measured droplets sizes are exhibited for selected axial distances from the nozzle-tip for the complete temporal measurement interval in Fig. 10. The histograms show a very similar frequency distribution with no significant differences for both fuels. At $60 \mathrm{~mm}$ from the nozzle tip, for E20 the highest frequency probability is shifted to smaller droplets with increasing 


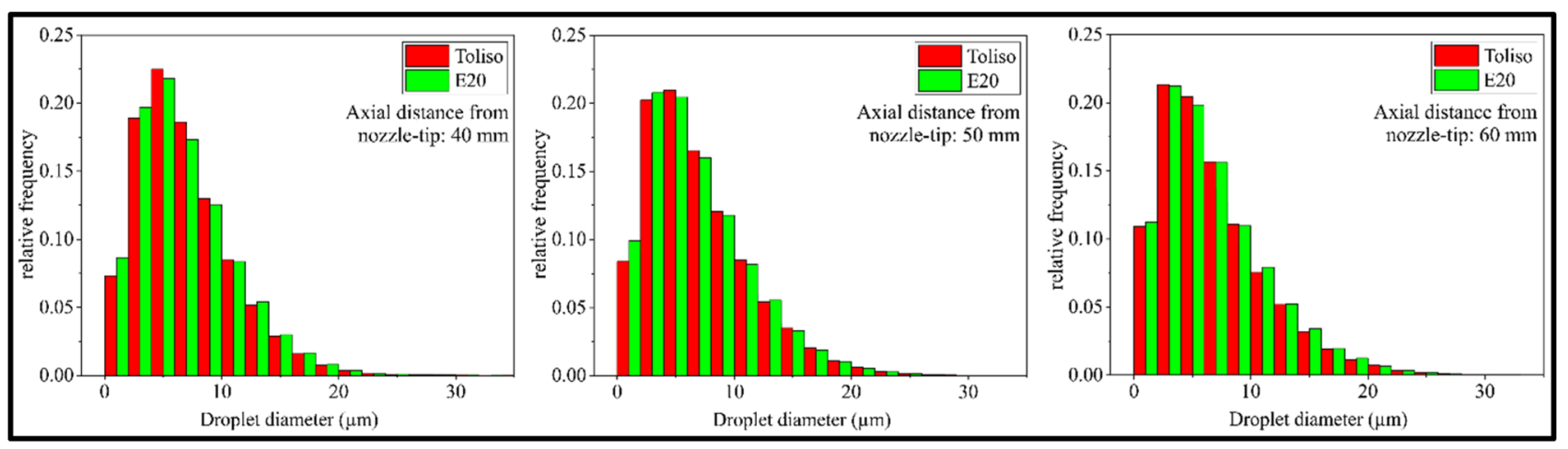

Fig. 10 Normalized droplet size histograms of Toliso and E20 for various axial distances from the nozzle-tip for the complete time interval measured by PDA (0.8-3 ms aESOI)

axial distance from the nozzle-tip. This effect might be caused by increased droplet evaporation, which is incorporated with turbulent droplet dispersion and increased air entrainment for larger axial distances from the nozzle-tip. E20 shows a slightly higher relative frequency for larger droplets (larger than $10 \mu \mathrm{m}$ ) than ethanol. However, this difference is smaller than expected from predictions of the model of Hiroyasu and Arai (1990) (see also Table 4). It can be concluded from PDA and PDS-SMD measurements that an ethanol addition of $20 \%$ has no distinct effect on atomization and just a small influence on evaporation for the studied injection conditions. Only few droplets between $20 \mu \mathrm{m}$ and $30 \mu \mathrm{m}$ were detected, which is different from the PDS data showing a significant number of larger droplets for later points in time (see Fig. 5). This discrepancy could be due to droplet deformation effects, which will introduce errors in both techniques. Especially larger droplets tend to be nonspherical, but they are not validated in PDA. Also, evaporation could lead to distinct errors of the PDS-measured SMD, which will be discussed in the subsequent sections.

\subsection{Simulation of droplet evaporation effects on the accuracy of the PDS technique}

The evaporation effect on the accuracy of the PDS-technique has to be analyzed in detail. For this purpose, a numerical model is utilized that is capable to describe the different sources of error (such as temperature and dye concentration effects) on the accuracy of the PDS technique. Furthermore, the effect of the fuel properties on evaporation will be discussed here. On the one hand, ethanol has a lower boiling point than Toliso. On the other hand, the evaporation enthalpy of ethanol is three times larger than those of toluene and isooctane (see Table 2). These effects will result in a higher evaporation rate of Toliso and E20 in comparison to ethanol and can lead to larger systematic errors for the droplet size determination. As mentioned in Sect. 2.3, the model assumes isolated single droplets. This means that the evaporation rate will be larger than in a dense spray, which is characterized by locally higher vapor concentration between neighboring droplets. Since the real evaporation rate and the vapor concentration around the droplets are not known, the model results can be treated as a worst-case scenario for error estimations of the PDS-technique.

A considerable uncertainty factor is the droplet temperature. As the LIF-signal of Toliso and E20 is slightly temperature-dependent (Koegl et al. 2019b), an evaporation driven temperature change of the droplet can lead to further measurement uncertainties. The surface and core temperatures of the droplets with various sizes are shown in Fig. 11. In spite of different initial droplet sizes, similar temperatures during evaporation result for the respective fuel. After $1.2 \mathrm{~ms}$, the smallest temperature drop (for $10 \mu \mathrm{m}, 20 \mu \mathrm{m}$ and $30 \mu \mathrm{m}$ ) is observed for Toliso $(\approx 15 \mathrm{~K})$ followed by ethanol $(\approx 17 \mathrm{~K})$ and $\mathrm{E} 20(\approx 20 \mathrm{~K})$. Assuming a temperature drop of $20 \mathrm{~K}$ (from 293 to $273 \mathrm{~K}$ ) would lead to a reduction in LIF intensity of about $2.3 \%$ (Toliso) and $5.1 \%$ (E20) (Koegl et al. 2019b). This would result in a similar change in the LIF/ Mie-ratio (as the Mie-signal is just slightly temperature sensitive) and measured droplet size, respectively. For example, a $20 \mu \mathrm{m}$-droplet would be underestimated as $19.5 \mu \mathrm{m}$ (Toliso) or $19.0 \mu \mathrm{m}$ (E20).

The initial reduction in droplet temperature is strongly dependent on the heat loss of the droplet through evaporation, which is in turn dependent on the evaporated fuel mass and the evaporation enthalpy of the different components. Figure 13 shows that the mixtures E20 and Toliso exhibit a similar rate of evaporation while E100 shows a much lower rate. The influence of the evaporation enthalpy is reflected in the simulated total heat loss due to evaporation for an initial droplet diameter of $10 \mu \mathrm{m}$, which is given in Fig. 12 . The diagram shows the same correlation as the temperature profiles, where E20 has the highest total heat loss and the highest drop in temperature followed by E100 and Toliso. 


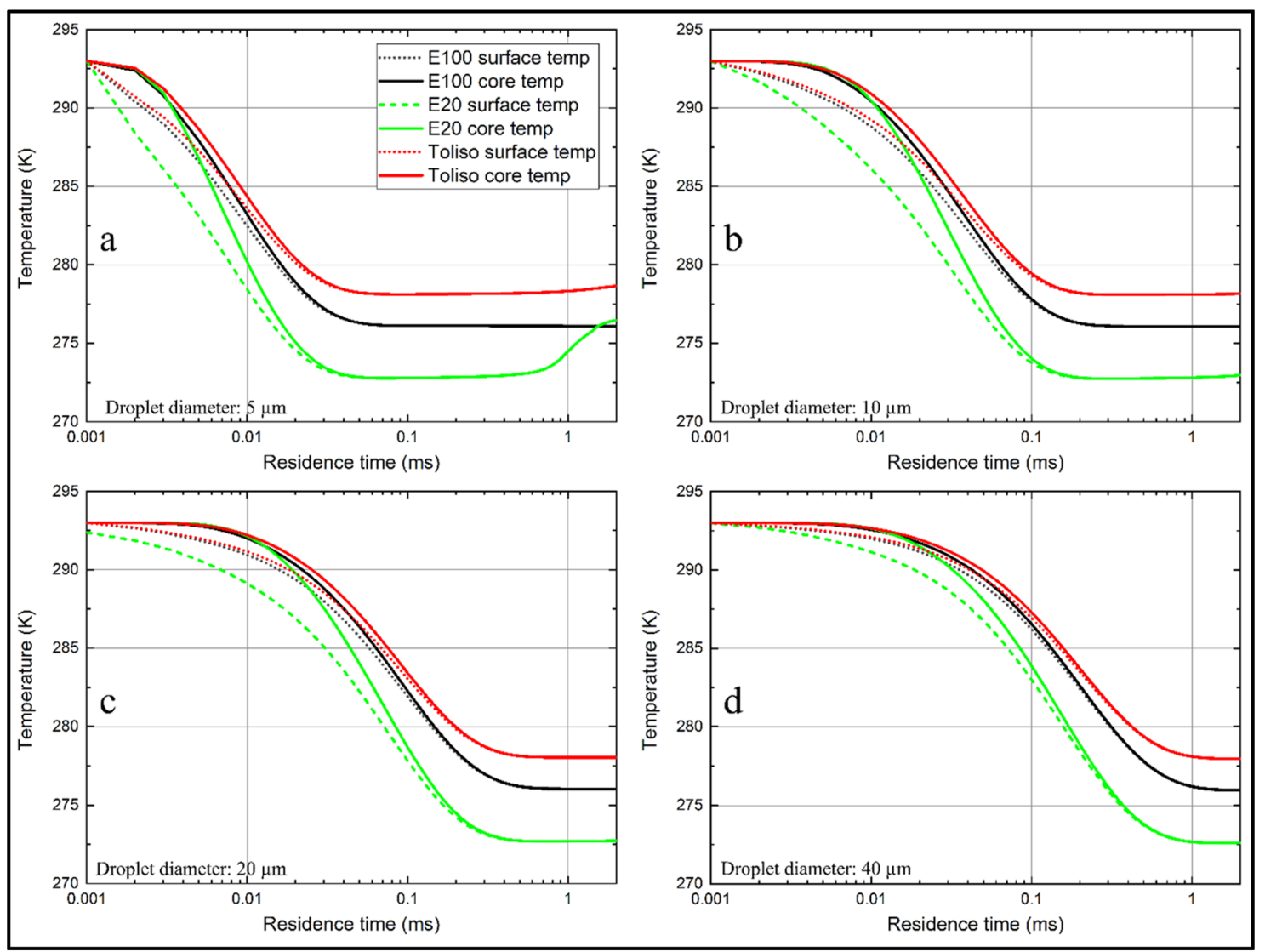

Fig. 11 Simulation of the surface and core temperature of evaporating fuel droplets for various initial droplet sizes and fuels. a Initial droplet diameter of $5 \mu \mathrm{m}, \mathbf{b} 10 \mu \mathrm{m}, \mathbf{c} 20 \mu \mathrm{m}$ and $\mathbf{d} 40 \mu \mathrm{m}$

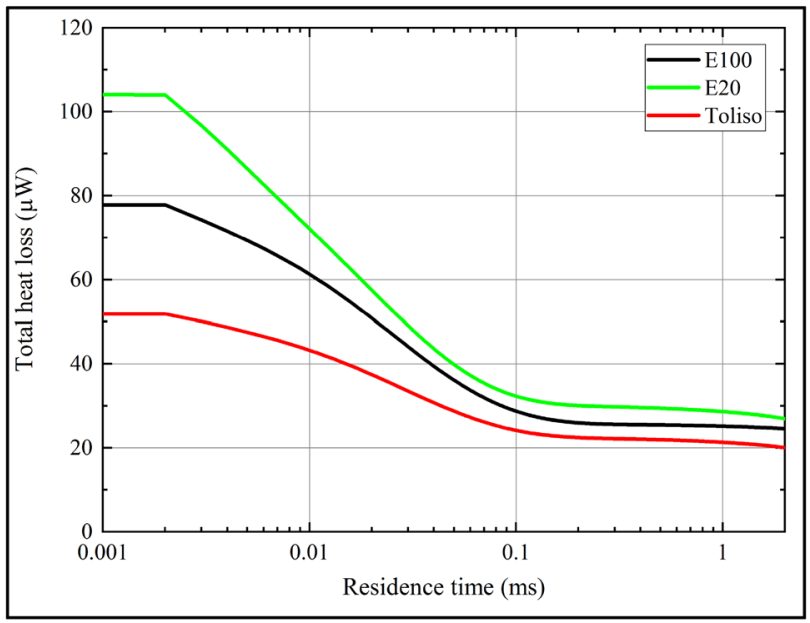

Fig. 12 Simulation of the total heat loss of evaporating $10 \mu \mathrm{m}$ fuel droplets for various fuel mixtures, $293 \mathrm{~K}, 0.2 \mathrm{MPa}$

Another important uncertainty factor is the varying droplet size and dye concentration during evaporation. For this purpose, the droplet lifetime is calculated for Toliso, E20

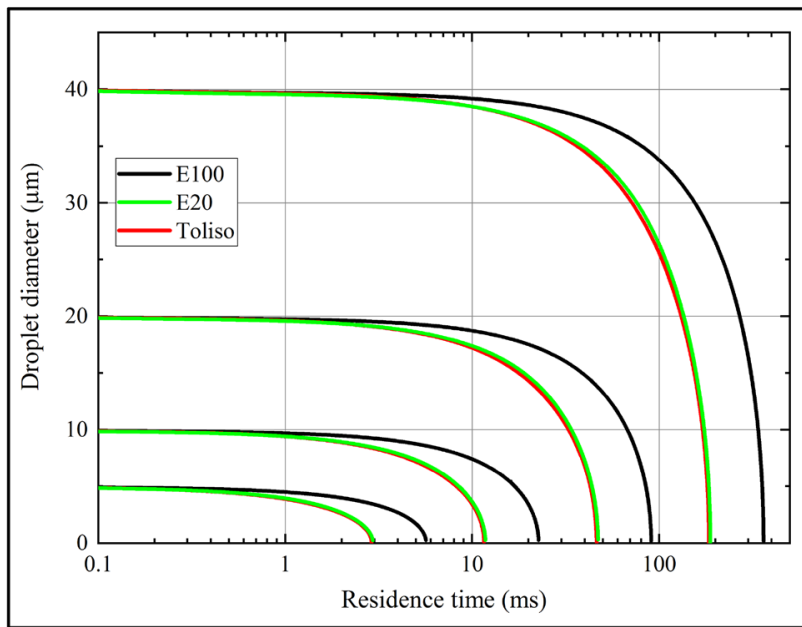

Fig. 13 Simulation of evaporating fuel droplets for various initial droplet sizes and for various fuel mixtures

and pure ethanol for different droplet sizes. Pure ethanol was chosen as an extreme case with a very low evaporation rate to discuss its influence on the droplet lifetime. Four relevant 
droplet size classes were simulated $(5-40 \mu \mathrm{m})$. The most relevant initial droplet sizes for evaluation of the evaporation effect on the uncertainty are $10 \mu \mathrm{m}$ and $20 \mu \mathrm{m}$ for the main spray region as average SMD are typically larger than $10 \mu \mathrm{m}$ (see Fig. 9). The evaporation effect on the droplet size is shown in Fig. 13.

The simulation results show an approximately double lifetime for ethanol for all simulated droplet sizes compared to Toliso and E20. E20 shows a slightly longer droplet lifetime in comparison to the base fuel Toliso due to the increase of the mixture evaporation enthalpy. Furthermore, already at $1.2 \mathrm{~ms}$ the droplet diameter of Toliso is reduced by $6.9 \%$ and $6.8 \%$ for E20 for an initially $10 \mu \mathrm{m}$ large droplet (while the reduction is about $3.4 \%$ for ethanol). This could explain that the evaporation effect is less distinct at early residence times leading to similar PDS-measured SMD. However, at $2 \mathrm{ms,}$ the droplet diameter is reduced by $11.2 \%$ for Toliso and $10.8 \%$ for E20 (while the reduction is about $3.4 \%$ for ethanol). Furthermore, the evaporation rate of E20 is still lower, which could partially explain the slightly larger droplets for E20 measured with SLIPI LIF/Mie and PDA at $2000 \mu$ s. The evaporation of Toliso and E20 leads to an increase of the dye concentration within the droplets. The time dependent dye concentrations in the respective droplets are given in Fig. 14.

The dye enrichment is a serious systematic error, which is distinct especially for small droplet sizes (e.g. $5 \mu \mathrm{m}$ ) occurring already after $100 \mu \mathrm{s}$. For a $10 \mu \mathrm{m}$ droplet, the dye enrichment is significant after $1.2 \mathrm{~ms}$ : For Toliso and E20, the dye concentration rises for a $10 \mu \mathrm{m}$ droplet by $20.4 \%$ (5 $\mu \mathrm{m}: 156.0 \%$ (Toliso), $140.8 \%$ (E20); $20 \mu \mathrm{m}$ : 6.2\% (Toliso and E20); $40 \mu \mathrm{m}$ : 3.1\% (Toliso and E20)), which would result in an overestimation of the droplet size measured via PDS of the same percentage as well. For pure ethanol, this effect is less pronounced ( $5 \mu \mathrm{m}$ : $46.3 \%$;

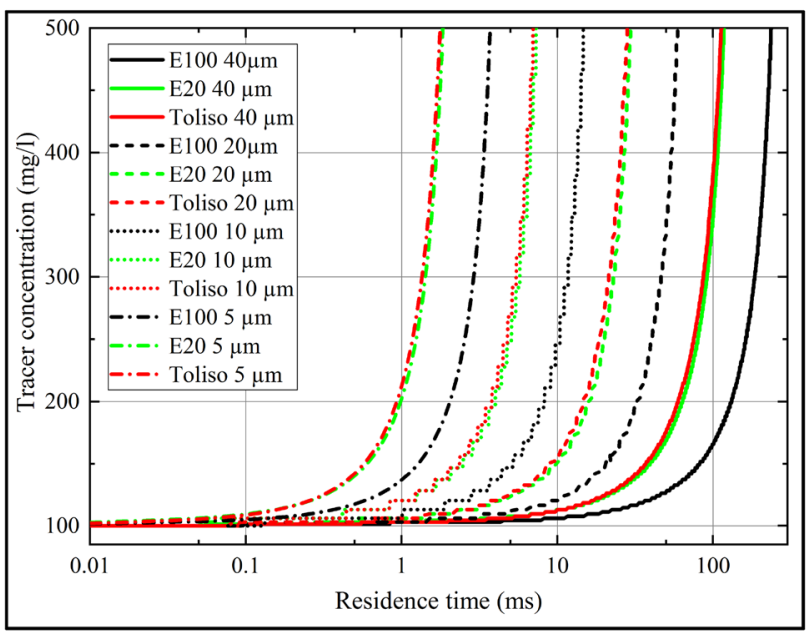

Fig. 14 Simulation of the tracer concentration in evaporating fuel droplets for various initial droplet sizes and fuel mixtures
$10 \mu \mathrm{m}: 13.0 \%$; $20 \mu \mathrm{m}: 3.1 \%$; $40 \mu \mathrm{m}: 3.1 \%$ ) due to its high evaporation enthalpy, which was also confirmed in previous measurements (Koegl et al. 2018b; Mishra et al. 2019). This means that large deviations between PDA and PDS can be mainly explained by dye enrichment. As the average SMD is in the range of 10-20 $\mu \mathrm{m}$, the dye enrichment would introduce errors between about 6-20\% for the present spray at $1.2 \mathrm{~ms}$, assumed that the LIF-signal is proportional to the dye concentration. Previous investigations (Koegl et al. 2019c) showed, that the LIF/Mie-ratio of Nile red dissolved in E20 increases linearly with increasing dye-concentration. The study revealed that the varied absorption due to the dye concentration can be neglected up to $200 \mathrm{mg} / \mathrm{l}$. However, it should be noted that PDA would also introduce uncertainties in the range of at least $4 \%$ in dilute spray regions without significant multiple scattering (Jermy and Greenhalgh 2000). Furthermore, for unsteady sprays, the PDA-technique may provide very low measurement data rates in regions with low droplet concentrations (Fdida et al. 2010). This may result in a bias of average SMD in case that only few droplets can be collected, which is especially problematic when short time intervals are analyzed in terms of a temporal spray analysis.

It can be concluded that with the present PDS-concept, a reliable droplet size determination is only possible at moderate temperatures (e.g. low evaporation rates) in combination with short residence times. It seems feasible that, however, e.g., in combination with suitable numerical modeling the PDS approach may be extended also to situations where significant evaporation occurs.

\section{Conclusion}

The spray structure of a gasoline DISI injector was analyzed in terms of droplet sizes (SMD). The surrogate gasoline Toliso (65 vol.\% isooctane, $35 \mathrm{vol} \% \%$ toluene) and the ethanol blend E20 (80 vol.\% Toliso, 20 vol.\% ethanol) were studied with planar droplet sizing using the fluorescence tracer Nile red. The qualitative LIF/Mie ratio of the DISIspray was calibrated with suitable calibration curves from an earlier investigation (Koegl et al. 2019c) with a droplet generator. The DISI-spray was recorded using the 2 p-SLIPI technique to effectively suppress multiple light scattering. The investigated droplet sizes in the sprays were in the range of $5 \mu \mathrm{m}$ up to $30 \mu \mathrm{m}$ and larger. The largest droplet sizes were located at the spray front and the lateral spray edges. An analysis of the spray fluctuations showed similar results for both investigated fuels. The highest fluctuations occur at the spray front and the lateral spray edges. Under the studied injection conditions, the SMDs of the Toliso and E20 sprays were similar and no pronounced fuel-dependent atomization was observed. The PDS and PDA measurements showed very similar SMD at short residence times (i.e. up to 
$1.2 \mathrm{~ms}$ ) at which evaporation is less distinct. At later observation times (i.e., $2 \mathrm{~ms}$ ) E20 showed an increased number of slightly larger droplets in PDA measurements. The offset between the PDS- and PDA- measured SMDs was in the range of $10 \%$ at $1.2 \mathrm{~ms}$. For longer residence times and an increased evaporation rate, the deviation between PDA- and PDS-measured SMD increased to roughly $50 \%$. A partial evaporation of the droplets leads to an enrichment of the tracer concentration resulting in large systematic errors of the measured SMD. A numerical simulation of single droplets showed that distinct tracer enrichment in the droplets occurs already after $1.2 \mathrm{~ms}$. This would result in an overestimation of the SMD in the range of about $6 \%$ for initially $20 \mu \mathrm{m}$ large droplets and of about $20 \%$ for $10 \mu \mathrm{m}$ large droplets, respectively. A temperature drop due to evaporation results in an error of the SMD in the range of 5\% under the studied conditions. Hence, the PDS-technique used in the present study is only applicable for operating conditions at which reduced evaporation occurs. The numerical simulation of isolated single droplets predicts faster evaporation than in a spray. Consequently, the model represents a worstcase scenario as the dye concentration in the droplet would be over-estimated for a given droplet lifetime. The model thus gives an upper bound for the uncertainty. The PDS technique should be expanded in the future regarding a combined application of experimental and numerical approaches.

Acknowledgements The authors gratefully acknowledge funding of the Erlangen Graduate School in Advanced Optical Technologies (SAOT) by the Bavarian State Ministry for Science and Art. The authors thank Dr. Edouard Berrocal (Lund University) for the fruitful collaboration on the SLIPI and spray diagnostics work.

Author contributions $\mathrm{KB}$ and MK performed the measurements; MK performed the data evaluation; YNM optimized the SLIPI post processing; BL and MK performed the PDA-measurements; C.C. performed the numerical simulation; LZ supervised the experiments and simulations; MK, LZ, CC and SW wrote the paper.

Funding Open Access funding provided by Projekt DEAL.

Open Access This article is licensed under a Creative Commons Attribution 4.0 International License, which permits use, sharing, adaptation, distribution and reproduction in any medium or format, as long as you give appropriate credit to the original author(s) and the source, provide a link to the Creative Commons licence, and indicate if changes were made. The images or other third party material in this article are included in the article's Creative Commons licence, unless indicated otherwise in a credit line to the material. If material is not included in the article's Creative Commons licence and your intended use is not permitted by statutory regulation or exceeds the permitted use, you will need to obtain permission directly from the copyright holder. To view a copy of this licence, visit http://creativecommons.org/licenses/by/4.0/.

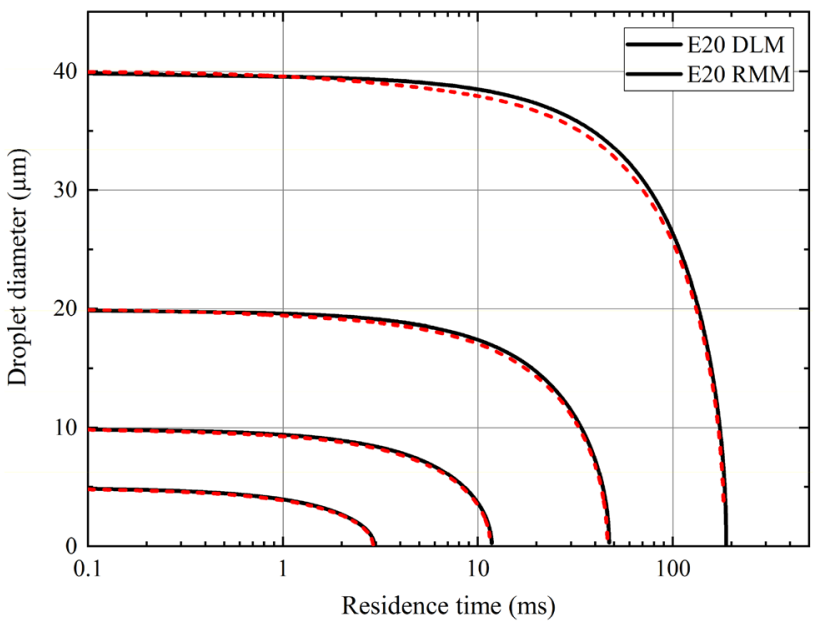

Fig. 15 Simulation of evaporating E20 droplets for various initial droplet sizes using the rapid mixing model (RRM) or diffusion-limited model (DLM), respectively

\section{Appendix}

This section presents additional information on the single droplet simulation. Figure 15 shows the evaporation behavior of isolated E20 droplets as predicted by the DLM and RMM, respectively.

The boundary conditions are the same as mentioned above. Under the given conditions, the differences in evaporation behavior for using the RMM and DLM are negligible. For toliso and E100, the differences between these two models are even smaller.

\section{References}

Abramzon B, Sirignano WA (1989) Droplet vaporization model for spray combustion calculations. Int J Heat Mass Transf 32(9):1605-1618. https://doi.org/10.1016/0017-9310(89)90043 $-4$

Bader A, Keller P, Hasse C (2013) The influence of non-ideal vaporliquid equilibrium on the evaporation of ethanol/iso-octane droplets. Int J Heat Mass Transf 64:547-558. https://doi.org/10.1016/j. ijheatmasstransfer.2013.04.056

Bronkhorst (2019) FLUIDAT on the Net. Available online: https:// www.fluidat.com. Accessed 24 Sep 2019

Burri J, Crockett R, Hany R, Rentsch D (2004) Gasoline composition determined by 1H NMR spectroscopy. Fuel 83(2):187-193. https ://doi.org/10.1016/s0016-2361(03)00261-8

Charalampous G, Hardalupas Y (2011a) Method to reduce errors of droplet sizing based on the ratio of fluorescent and scattered light intensities (laser-induced fluorescence/Mie technique). Appl Opt 50(20):3622-3637. https://doi.org/10.1364/AO.50.003622

Charalampous G, Hardalupas Y (2011b) Numerical evaluation of droplet sizing based on the ratio of fluorescent and scattered light intensities (LIF/Mie technique). Appl Opt 50(9):1197-1209. https ://doi.org/10.1364/AO.50.001197 
Chen L, Stone R (2011) Measurement of enthalpies of vaporization of isooctane and ethanol blends and their effects on PM emissions from a GDI engine. Energy Fuels 25(3):1254-1259. https://doi. org/10.1021/ef1015796

Choi BC, Choi SK, Chung SH (2011) Soot formation characteristics of gasoline surrogate fuels in counterflow diffusion flames. Proc Combust Inst 33:609-616. https://doi.org/10.1016/j.proci 2010.06.067

Christensen E, Yanowitz J, Ratcliff M, McCormick RL (2011) Renewable oxygenate blending effects on gasoline properties. Energy Fuels 25(10):4723-4733. https://doi.org/10.1021/ef2010089

Dean JA (1999) Lange's handbook of chemistry, 15th edn. McGrawHill Companies, New York

Depredurand V, Miron P, Labergue A, Wolff M, Castanet G, Lemoine F (2008) A temperature-sensitive tracer suitable for two-colour laser-induced fluorescence thermometry applied to evaporating fuel droplets. Meas Sci Technol. https://doi.org/10.1088/09570233/19/10/105403

Depredurand V, Castanet G, Lemoine F (2010) Heat and mass transfer in evaporating droplets in interaction: Influence of the fuel. Int J Heat Mass Transf 53(17-18):3495-3502. https://doi. org/10.1016/j.jjheatmasstransfer.2010.04.010

Domann R, Hardalupas Y (2001a) Spatial distribution of fluorescence intensity within large droplets and its dependence on dye concentration. Appl Opt 40(21):3586-3597. https://doi.org/10.1364/ AO.40.003586

Domann R, Hardalupas Y (2001b) A Study of parameters that influence the accuracy of the planar droplet sizing (PDS) Technique. Part Part Syst Charact 18(1):3-11. https://doi.org/10.1002/15214117(200102)18:1<3:aid-ppsc3>3.0.co;2-\#

Domann R, Hardalupas Y (2003) Quantitative measurement of planar droplet sauter mean diameter in sprays using planar droplet sizing. Part Part Syst Charact 20(3):209-218. https://doi.org/10.1002/ ppsc. 200390027

Domann R, Hardalupas Y, Jones AR (2002) A study of the influence of absorption on the spatial distribution of fluorescence intensity within large droplets using Mie theory, geometrical optics and imaging experiments. Meas Sci Technol 13:280-291. https://doi. org/10.1088/0957-0233/13/3/308

Durst A, Wensing M, Berrocal E (2018) Light sheet fluorescence microscopic imaging for the primary breakup of diesel and gasoline sprays with real-world fuels. Appl Opt 57:2704-2714. https ://doi.org/10.1364/AO.57.002704

Fdida N, Blaisot J-B, Floch A, Dechaume D (2010) Drop-size measurement techniques applied to gasoline sprays. At Sprays 20(2):141162. https://doi.org/10.1615/AtomizSpr.v20.i2.40

Fournier S, Simon G, Seers P (2016) Evaluation of low concentrations of ethanol, butanol, BE, and ABE blended with gasoline in a direct-injection, spark-ignition engine. Fuel 181:396-407

Frackowiak B, Tropea C (2010a) Fluorescence modeling of droplets intersecting a focused laser beam. Opt Lett 35(9):1386-1388. https://doi.org/10.1364/OL.35.001386

Frackowiak B, Tropea C (2010b) Numerical analysis of diameter influence on droplet fluorescence. Appl Opt 49(12):2363-2370. https ://doi.org/10.1364/AO.49.002363

Greenspan P, Fowler SD (1985) Spectrofluorometric studies of the lipid probe, Nile Red. J Lipid Res 26:781-789

Heldmann M, Bornschlegel S, Wensing M (2015) Investigation of Jetto-Jet Interaction in Sprays for DISI Engines. SAE Tech Paper. https://doi.org/10.4271/2015-01-1899

Hiroyasu H, Arai M (1990) Structures of fuel sprays in diesel engines. SAE Tech Paper. https://doi.org/10.4271/900475

Jermy MC, Greenhalgh DA (2000) Planar dropsizing by elastic and fluorescence scattering in sprays too dense for phase Doppler measurement. Appl Phys B 71(5):703-710. https://doi.org/10.1007/ s003400000404
Kalathimekkad S, Missinne J, Schaubroeck D, Mandamparambil R, Van Steenberge G (2015) Alcohol vapor sensor based on fluorescent dye-doped optical waveguides. IEEE Sens J 15:76-81. https ://doi.org/10.1109/JSEN.2014.2338916

Kawaguchi T, Akasaka Y, Maeda M (2002) Size measurements of droplets and bubbles by advanced interferometric laser imaging technique. Meas Sci Technol 13(3):308-316. https://doi. org/10.1088/0957-0233/13/3/312

Keller P, Bader A, Hasse C (2013) The influence of intra-droplet heat and mass transfer limitations in evaporation of binary hydrocarbon mixtures. Int J Heat Mass Transf 67:1191-1207. https://doi. org/10.1016/j.ijheatmasstransfer.2013.08.104

Knorsch T, Heldmann M, Zigan L, Wensing M, Leipertz A (2013) On the role of physiochemical properties on evaporation behavior of DISI biofuel sprays. Exp Fluids. https://doi.org/10.1007/s0034 8-013-1522-6

Koegl M, Hofbeck B, Will S, Zigan L (2018a) Investigation of soot formation and oxidation of ethanol and butanol fuel blends in a DISI engine at different exhaust gas recirculation rates. Appl Energy 209:426-434. https://doi.org/10.1016/j.apenergy.2017.11.034

Koegl M, Hofbeck B, Baderschneider K, Mishra YN, Huber FJT, Berrocal E, Will S, Zigan L (2018b) Analysis of LIF and Mie signals from single micrometric droplets for instantaneous droplet sizing in sprays. Opt Express 26(24):31750-31766. https://doi. org/10.1364/OE.26.031750

Koegl M, Mishra YN, Hofbeck B, Baderschneider K, Huber FJT, Pracht J, Berrocal E, Will S, Zigan L (2018c) 3D LIF/Mie planar droplet sizing in IC engine sprays using single-droplet calibration data. In: ICLASS 2018: 14th International Conference on liquid atomization \& spray systems, Chicago, 2018.

Koegl M, Mishra YN, Storch M, Conrad C, Berrocal E, Will S, Zigan L (2019a) Analysis of ethanol and butanol direct-injection sparkignition sprays using two-phase structured laser illumination planar imaging droplet sizing. Int J Spray Combust Dyn. https://doi. org/10.1177/1756827718772496

Koegl M, Mull C, Baderschneider K, Wislicenus J, Will S, Zigan L (2019b) Characterization of Nile red as a tracer for laser-induced fluorescence spectroscopy of gasoline and kerosene and their mixture with biofuels. Sensors 19(12):2822

Koegl M, Baderschneider K, Bauer F, Hofbeck B, Berrocal E, Will S, Zigan L (2019c) Analysis of the LIF/Mie ratio from individual droplets for planar droplet sizing: application to gasoline fuels and their mixtures with ethanol. Appl Sci. https://doi.org/10.3390/ app9224900

Koegl M, Hofbeck B, Will S, Zigan L (2019d) Influence of EGR and ethanol blending on soot formation in a DISI engine. Proc Combust Inst 37(4):4965-4972. https://doi.org/10.1016/j.proci .2018 .07 .103

Le Gal P, Farrugia N, Greenhalgh DA (1999) Laser Sheet Dropsizing of dense sprays. Opt Laser Technol 31(1):75-83. https://doi. org/10.1016/S0030-3992(99)00024-9

Lin BS, Yang YC, Ho CY, Yang HY, Wang HY (2014) A PDMSbased cylindrical hybrid lens for enhanced fluorescence detection in microfluidic systems. Sensors 14(2):2967-2980. https:// doi.org/10.3390/s140202967

Luning Prak DJ, Cowart JS, Trulove PC (2014) Density, viscosity, speed of sound, bulk modulus, and surface tension of binary mixtures of n-Heptane + 2,2,4-Trimethylpentane at (293.15 to 338.15) $\mathrm{K}$ and 0.1 MPa. J Chem Eng Data 59(11):3842-3851. https://doi. org/10.1021/je5007532

Malarski A, Schurer B, Schmitz I, Zigan L, Flugel A, Leipertz A (2009) Laser sheet dropsizing based on two-dimensional Raman and Mie scattering. Appl Opt 48(10):1853-1860. https://doi.org/10.1364/ AO.48.001853

Mishra YN, Kristensson E, Berrocal E (2014) Reliable LIF/Mie droplet sizing in sprays using structured laser illumination planar 
imaging. Opt Express 22(4):4480-4492. https://doi.org/10.1364/ OE.22.004480

Mishra YN, Kristensson E, Koegl M, Joensson J, Zigan L, Berrocal E (2017) Comparison between two-phase and one-phase SLIPI for instantaneous imaging of transient sprays. Exp Fluids. https://doi. org/10.1007/s00348-017-2396-9

Mishra YN, Koegl M, Baderschneider K, Hofbeck B, Berrocal E, Conrad C, Will S, Zigan L (2019) 3D mapping of droplet Sauter mean diameter in sprays. Appl Opt 58(14):3775-3783. https://doi. org/10.1364/AO.58.003775

Moon S, Choi J, Abo-Serie E, Bae C (2005) The effects of injector temperature on spray and combustion characteristics in a single cylinder DISI engine. In: SAE International: 2005

Mounaïm-Rousselle C, Pajot O (1999) Droplet sizing by mie scattering interferometry in a spark ignition engine. Part Part Syst Charact 16(4):160-168. https://doi.org/10.1002/(sici)1521-4117(19990 8) $16: 4<160$ :aid-ppsc160>3.0.co;2-g

Palmer J, Reddemann M, Kirsch V, Kneer R (2018) Applying 2D-2cLIF-EET thermometry for micro-droplet internal temperature imaging. Exp Fluids. https://doi.org/10.1007/s0034 8-018-2506-3

Park S, Cho H, Yoon I, Min K (2002) Measurement of droplet size distribution of gasoline direct injection spray by droplet generator and planar image technique. Meas Sci Technol 13(6):859-864. https://doi.org/10.1088/0957-0233/13/6/305

Reichardt C, Welton T (2010) Solvents and solvent effects in organic chemistry, 4th edn. WILEY-VCH Verlag GmbH \& KGaA, Weinheim

Robert Bosch GmbH (2011) Kraftfahrtechnisches Taschenbuch, 27th. Aufl. ed. edn. ViewegTeubner Verlag, Wiesbaden

Schirmer RE (1990) Modern methods of pharmaceutical analysis, 2nd edn. Taylor \& Francis, Milton Park

Shirazi AS, Abdollahipoor B, Martinson J, Windom B, Foust T, Reardon K (2019) Effects of dual-alcohol gasoline blends on physiochemical properties and volatility behavior. Fuel 252:542-552. https://doi.org/10.1016/j.fuel.2019.04.105

Storch M, Zigan L, Wensing M, Will S (2014) Systematic investigation of the influence of ethanol blending on sooting combustion in DISI engines using high-speed imaging and LII. SAE Techn Paper. https://doi.org/10.4271/2014-01-2617

Storch M, Hinrichsen F, Wensing M, Will S, Zigan L (2015) The effect of ethanol blending on mixture formation, combustion and soot emission studied in an optical DISI engine. Appl Energy 156:783792. https://doi.org/10.1016/j.apenergy.2015.06.030

Storch M, Lind S, Will S, Zigan L (2016a) Influence of ethanol admixture on the determination of equivalence ratios in DISI engines by laser-induced fluorescence. Appl Opt 55(30):8532-8540. https:// doi.org/10.1364/AO.55.008532

Storch M, Mishra YN, Koegl M, Kristensson E, Will S, Zigan L, Berrocal E (2016b) Two-phase SLIPI for instantaneous LIF and Mie imaging of transient fuel sprays. Opt Lett 41(23):5422-5425. https ://doi.org/10.1364/OL.41.005422

Storch M, Pfaffenberger A, Koegl M, Will S, Zigan L (2016c) Combustion and sooting behavior of spark-ignited ethanol-isooctane sprays under stratified charge conditions. Energy Fuels 30(7):6080-6090. https://doi.org/10.1021/acs.energyfuels.6b004 33

Storch M, Koegl M, Altenhoff M, Will S, Zigan L (2016d) Investigation of soot formation of spark-ignited ethanol-blended gasoline sprays with single- and multi-component base fuels. Appl Energy 181:278-287. https://doi.org/10.1016/j.apenergy.2016.08.059

VDI-Gesellschaft Verfahrenstechnik und Chemieingenieurwesen (2013) VDI-Wärmeatlas. 11. Aufl. ed. Springer-Verlag, Berlin

Wang F, Wu J, Liu Z (2006) Surface tensions of mixtures of diesel oil or gasoline and dimethoxymethane, dimethyl carbonate, or ethanol. Energy Fuels 20(6):2471-2474. https://doi.org/10.1021/ ef060231c

Welss R, Bornschlegel S, Wensing M (2018) Characterizing spray propagation of GDI injectors under crossflow conditions. SAE Tech Paper. https://doi.org/10.4271/2018-01-1696

Wilms J (2005) Evaporation of multicomponent droplets. Dissertation, Universität Stuttgart, Verlag Dr. Hut, München, 2005.

Zeng W, Xu M, Zhang YY, Wang ZK (2013) Laser sheet dropsizing of evaporating sprays using simultaneous LIEF/MIE techniques. Proc Combust Inst 34:1677-1685. https://doi.org/10.1016/j.proci .2012.07.061

Zhang Y, Leng J, Hu W (2018) Theoretical design of a two-photon fluorescent probe for nitric oxide with enhanced emission induced by photoninduced electron transfer. Sensors. https://doi.org/10.3390/ s18051324

Zigan L, Schmitz I, Flugel A, Knorsch T, Wensing M, Leipertz A (2010) Effect of fuel properties on spray breakup and evaporation studied for a multihole direct injection spark ignition injector. Energy Fuels 24(8):4341-4350. https://doi.org/10.1021/ef100 3914

Publisher's Note Springer Nature remains neutral with regard tojurisdictional claims in published maps and institutional affiliations. 